\title{
Lidar study of unusual winter Saharan dust loads above Sofia, Bulgaria: impacts on the local weather and troposphere
}

\author{
Atanaska Deleva, Zahari Peshev,* Liliya Vulkova $\odot$, and Tanja Dreischuh \\ Institute of Electronics, Bulgarian Academy of Sciences, Sofia, Bulgaria
}

\begin{abstract}
We report results of lidar studies of the atmospheric aerosols present above the city of Sofia during four episodes of wintertime Saharan dust intrusions in the last decade. The optical and microphysical properties of the detected aerosols, as well as the aerosol layering and dynamics, are retrieved and characterized. By combining lidar results with in situ $\mathrm{PM}_{10}$ concentration measurement data and air-transport modeling/forecast data, the effects of mixing and interaction of desert aerosols with local ones are analyzed as dependent on the altitude range, phase, and intensity of the dust load events. Included in the analysis are also meteorological radiosonde data, which allow us to ascertain the direct and strong influence of the desert air and aerosols on the local atmospheric conditions and meteorological parameters and thus, indirectly, on essential components of the local weather, such as the seasonal thermal regime and the regimes of cloud formation and precipitation. Using online resources, color maps of air temperature anomalies in the region for the days of lidar measurements are also provided based on climatological data over the three preceding decades. The results presented are in conformity with previously published statistical data of other authors and indicate that the wintertime intrusions of warm air masses from North Africa carrying Saharan dust to Europe, and particularly to the Balkans, rare and atypical until recently, nowadays show a trend of increasing in terms of frequency and intensity, pointing to deviations in the seasonal regime of the involved intercontinental air circulation systems. (1) The Authors. Published by SPIE under a Creative Commons Attribution 4.0 Unported License. Distribution or reproduction of this work in whole or in part requires full attribution of the original publication, including its DOI. [DOI: 10.1117/1.JRS.15.024517]
\end{abstract}

Keywords: atmospheric aerosols; Saharan dust; lidar; aerosol backscatter; aerosol dynamics; Ångström exponent; local weather; winter.

Paper 200841 received Nov. 27, 2020; accepted for publication May 12, 2021; published online May 28, 2021.

\section{Introduction}

The rise in the mean annual atmospheric temperature of Earth's climate system, known as global warming, has shown a distinct and sustainable trend over the last few decades, ${ }^{1}$ being at present clearly evident even on regional and local scales. Along with the greenhouse gasses, mineral aerosols (dust) play an important role in the phenomenon. ${ }^{2}$ Dust emissions into the atmosphere result from various natural processes and human activities. The biggest source of natural mineral aerosols on Earth is the Sahara Desert. ${ }^{3}$ Huge amounts of airborne desert dust are frequently transported north-eastward to the Mediterranean and Europe each year. ${ }^{4-13}$ Intrusions of Saharan dust over Europe mostly take place in spring and summer, as observations by ground-based and air/space-born apparatus have shown. In winter, the European continent is predominantly invaded by cold frontal systems from the north; therefore, events of desert dust transport are less probable and, as a rule, rare ${ }^{5-7,10}$ However, cases of the presence of Saharan dust in the atmosphere above Europe in winter months have multiplied, as proven by satellite, in situ, and lidar observations conducted during the last several years. ${ }^{8,11,14-22}$

The massive load of desert dust into the atmosphere and its subsequent long-range transport over vast geographic areas has various and strong effects on the global and regional climate, atmospheric conditions, processes, and air circulations, as well as on ecosystems and human

*Address all correspondence to Zahari Peshev, zypeshev@ie.bas.bg 
health. ${ }^{1,23-28}$ Furthermore, when the events of atmospheric mineral dust intrusions at middle and high latitudes take place during the winter season, these effects have more specific and much stronger manifestations. The climate-related effects of Saharan dust can then be regarded in two aspects. First, the transfer of unusually hot desert air masses to much colder atmospheric regions that causes the wintertime occurrence of desert dust at the mentioned latitudes could be regarded as a natural result of, and an indication for changes in, the typical seasonal regime of synopticscale air circulations. This is normally accompanied by an anomalous (for the season) increase of the regional and local air temperature. In recent years, events of long-range wintertime dust/heat transfer over Europe have been observed quite frequently. ${ }^{11}$ Therefore, they could be considered a manifestation of the possibly emerging changes mentioned above in the seasonal atmospheric circulation systems that mobilize air masses from North Africa northeastward over the Mediterranean to Europe. These could also be associated with likely changes in the regional climate system.

Moreover, the atmospheric thermal and radiative balance can be severely affected and perturbed due to the enormous amounts of dust particulate matter of predominantly large sizes being loaded, ${ }^{28}$ in view of the high radiative forcing potential of the desert aerosols. Second, in the quite common case of desert air/dust spreading near the surface, direct and/or indirect effects on the local air quality and, especially, on human health appear even in a stronger form, as in wintertime the human organism is vulnerable to seasonal colds and viral diseases. The mentioned significant climatic and health impacts of the Saharan dust intrusions make it sensible that such events be extensively monitored and studied.

Lidars are efficient and widely adopted instruments for conducting observations of atmospheric aerosol pollutants, including desert dust. ${ }^{6-9,12,17,18,29,30}$ They enable real-time measurements and assessments of atmospheric aerosols, establishing their optical, topological, and dynamical parameters over broad areas with high spatial and temporal resolution. Furthermore, the microphysical properties of mineral dust particles can also be determined and characterized qualitatively or quasi-quantitatively in terms of Ångström exponent ${ }^{31-33}$ evaluation and profiling by making use of two- or multi-wavelength lidars. ${ }^{34,35}$ A nearly complete characterization of the optical, physical, and microphysical properties of aerosol/dust particles (including determination of the particle size distribution and mass/volume concentration) can be achieved by combining multi-wavelength lidar measurement data with Sun-photometer data ${ }^{36}$ and applying newly developed synergistic theoretical approaches, such as GARRLiC and LIRIC. ${ }^{37-39}$

Extensive studies and permanent monitoring of Saharan dust events over Europe $\mathrm{e}^{30}$ have been a primary goal and subject of measurement activities and campaigns implemented in the framework of the European Aerosol Research Lidar Network (EARLINET). ${ }^{40}$ This is a key component of the European Research Infrastructure for the Observation of Aerosol, Clouds, and Trace Gases (ACTRIS). ${ }^{41}$

In this paper, we present results of lidar observations of unusual winter penetrations of dustrich air masses from the Sahara Desert into the atmosphere over Sofia, Bulgaria, performed on the 17th, 24th, 1st, and 18th of February in the years 2014, 2017, 2018, and 2019, respectively. The distinguishing feature of the meteorological conditions during these four days of lidar atmospheric measurement was that the air temperatures registered close to the surface were atypically high (in the range $10^{\circ} \mathrm{C}$ to $20^{\circ} \mathrm{C}$ ) for the Sofia region. More specifically, meteorological data showed that the maximum temperature recorded in Sofia on February 17, 2014, was $21^{\circ} \mathrm{C}$; February $24,2017,19^{\circ} \mathrm{C}$; February $1,2018,11^{\circ} \mathrm{C}$; and February $18,2019,14^{\circ} \mathrm{C}$. $^{42}$ It should be emphasized that such temperatures are very high for the month of February, as proved by the long-term systematic meteorological measurements in Sofia. According to them, February is defined as one of the coldest months of the year, with the climate normal average monthly temperature of $0.8^{\circ} \mathrm{C}$.

In Bulgaria, the weather fluctuations in February have become more frequent and significant during the last decade, being expressed in combining typical winter cold periods with unusually warm spring-like ones (with temperatures near and above $20^{\circ} \mathrm{C}$ ). In general, the rise in the air temperature in the region is caused by an invasion of warm air masses from the south and southwest. Therefore, the more frequent warm periods in February commented on above may be due in large part to winter air/dust transport from North Africa, particularly, from the Sahara Desert. 
Deleva et al.: Lidar study of unusual winter Saharan dust loads above Sofia, Bulgaria: impacts...

The objectives of this work are as follows:

(i) To present and analyze examples of significant intrusions of warm air masses carrying Saharan dust from North Africa over the Mediterranean to the region of Bulgaria taking place during the coldest months of the winter in recent years. To discuss the possibilities for the observed events to be related to possible deviations from the established seasonal regime of the regional atmospheric circulations in the broader context of ongoing climate changes;

(ii) To explore and characterize the optical and microphysical parameters of the observed aerosols, as well as the topological and dynamic features of the aerosol/dust field stratification;

(iii) To reveal the effects resulting from the mixing and interaction of desert particulate matter with local aerosols on their optical and microphysical properties, together with the effects resulting from the dust transport history;

(iv) To evaluate the influence of the atypical winter Saharan dust load events on local weather conditions and meteorological parameters.

In the following sections, results are presented and discussed related to the presence, topology, density distribution, temporal evolution, and microphysics of the Saharan dust layers observed.

\section{Measurement Site, Instrumentation, and Methods}

Bulgaria is situated in the central part of the Balkan Peninsula (in the Eastern Mediterranean basin). The only Bulgarian lidar station is located in the Laser Radars Laboratory (LRL) of the Institute of Electronics, Bulgarian Academy of Sciences, and has been part of the EARLINET network since 2002. The lidar site is positioned in an urban area of the capital city of Sofia $\left(42^{\circ} 39^{\prime} 14^{\prime \prime} \mathrm{N}, 23^{\circ} 23^{\prime} 14^{\prime \prime} \mathrm{E}\right)$. Topographically, Sofia is located at about $600 \mathrm{~m}$ above sea level (ASL) in a natural basin surrounded by mountains. Hereinafter, the cited values of elevation (height or altitude) are measured above ground level, unless it is explicitly stated that they are ASL. The time and time intervals are quoted in coordinated universal time (UTC). In the month of February, when all lidar measurements considered here were conducted, the local time (LT) in Bulgaria is the standard East European Time $(\mathrm{UTC}+2)$.

The wintertime Saharan dust events presented and discussed were studied by means of an aerosol lidar designed and built in the LRL. ${ }^{8,12,43}$ The lidar system is configured in a mono-static biaxial alignment pointing at an angle of $32 \mathrm{deg}$ with respect to the horizon, as determined by its position in the lab. Therefore, although signals from as far as $30 \mathrm{~km}$ can be recorded, the maximum sounding height is limited to about $16 \mathrm{~km}$. The light source is a solid-state $Q$-switched frequency-doubled Nd:YAG laser (pulse energy of up to $600 \mathrm{~mJ}$ at $1064 \mathrm{~nm}$ and $80 \mathrm{~mJ}$ at $532 \mathrm{~nm}$; pulse duration of $15 \mathrm{~ns}$ FWHM; laser-beam divergence of $3 \mathrm{mrad}$; fixed repetition rate of $2 \mathrm{~Hz}$ ). The light backscattered by atmospheric molecules and aerosol particles is received by a Cassegrain telescope (aperture of $35 \mathrm{~cm}$ and focal distance of $200 \mathrm{~cm}$ ). The lidar measures backscattered signals with a time/height resolution of $100 \mathrm{~ns} / 7.5 \mathrm{~m}$.

The Klett-Fernald's inversion algorithm is applied for retrieving the atmospheric aerosol backscatter coefficient (BSC) profiles ${ }^{44,45}$ using a constant lidar ratio (the ratio of aerosol extinction and backscattering coefficients) of 45 . We consider this value of the lidar ratio to be reasonable in cases of aerosols dominated by Saharan dust. ${ }^{46-48}$

The profiles are calibrated using values of the molecular BSC known from the standard atmosphere (SA) mode $^{49}$ for values measured of the close to the surface air pressure and temperature. The calibration altitude intervals of nearly pure molecular atmospheric content are determined by applying the standard Rayleigh fitting procedure. ${ }^{50,51}$

For each measurement cycle, we calculate the averaged aerosol BSC profile, and using a series of consecutively recorded range-corrected signals (RCS), a colormap in height-time coordinates is constructed, illustrating the spatial distribution and temporal dynamics of the aerosol fields detected. The profiles obtained at the two laser wavelengths (532 and $1064 \mathrm{~nm}$ ) are then used to calculate the corresponding profiles of the backscatter-related Ångström exponent (BAE), which is regarded as an indicator of the dominant particle size fraction in the aerosol 
layers registered. To make assumptions about both the type and origin of the aerosols in the layers detected by the lidar, we use the data and images provided by the Barcelona Supercomputing Center Dust Models (BSC-DM) BSC-DREAM8b and/or NMMB/BSCDust, ${ }^{52-54}$ as well the hybrid single-particle Lagrangian integrated trajectory (HYSPLIT) model, developed in the Air Resource Laboratory of National Oceanic and Atmospheric Administration (NOAA), USA. . $^{55,56}$

\section{Dust Transport Episodes}

\subsection{Dust Transport Model Forecasts}

Figure 1 presents the vertical profiles of the Saharan dust concentration (in $\mu \mathrm{g} / \mathrm{m}^{3}$ ) in the atmosphere above Sofia as forecasted by BSC-DM and colormaps (in the insets) of the dust-load magnitude (in $\mathrm{g} / \mathrm{m}^{2}$ ) related to the four-day measurements, the results of which are discussed and analyzed here. The Sofia region is marked by a red circle, and the heights are given in $\mathrm{km}$ ASL. The dust transport data for 2014 and 2017 are provided by the BSC-DREAM8b model; those for 2018, by the NMMB/BSC-Dust model; and for 2019, by a combination of the data provided by the models depending on their availability for the respective dates.

The dust maps in Fig. 1 show moderate-to-considerable dust loads above Bulgaria. A closer analysis of these BSC-DM forecasts reveals that the transport episodes that include the dates of lidar measurements considered here were as follows: episode 1: February 17 to 22, 2014; episode 2: February 24 to 27, 2017; episode 3: February 1 to 4, 2018; episode 4: February 3 to 21, 2019. Thus the first three measurements performed fell in the first part of the respective periods, whereas the last one took place closer to the end of a rather long transport episode.

The vertical profiles of the dust concentration in the air above Sofia provide more detailed information on the specificity of the separate transport events in question. Thus BSC-DREAM8b forecast for February 17, 2014, [Fig. 1(a)] indicates that the atmosphere above the city was loaded by Saharan dust from ground level $(600 \mathrm{~m} \mathrm{ASL})$ to a height of about $8 \mathrm{~km} \mathrm{ASL}$. The concentration was steeply increasing up to about $1 \mathrm{~km}$ ASL and rising rather slowly up to $3 \mathrm{~km}$ ASL. The aerosol layer's highest density occurred in the range 3 to $5 \mathrm{~km}$ ASL, with a maximum (about $70 \mu \mathrm{g} / \mathrm{m}^{3}$ ) at $4 \mathrm{~km}$ ASL. Above $5 \mathrm{~km}$ ASL, the dust load gradually receded. The conditions during the second set of lidar observations, as illustrated by the profile of February 24, 2017, [Fig. 1(b)] were characterized by dust loading from ground level to about $4 \mathrm{~km}$ ASL, the dust being located mainly within a layer with approximate boundaries 1.8 to $3.8 \mathrm{~km}$ ASL with the center of mass near $2.3 \mathrm{~km}$ ASL. In the case of February 1, 2018, we used the information made available by the NMMB/BSC-Dust model, namely, the atmosphere over the entire territory of Bulgaria was loaded by Saharan dust; above Sofia, the dust was located in the height interval 3 to $8 \mathrm{~km}$ ASL, with a higher concentration $\left(80\right.$ to $90 \mu \mathrm{g} / \mathrm{m}^{3}$ ) between 4.2 and $5.8 \mathrm{~km} \mathrm{ASL}$. In the last case considered here, that of February 18, 2019, we combined the information made available by the NMMB/BSC-Dust (dust-map) and the BSC-DREAM8b (dust concentration profile) models [Fig. 1(d)], which allowed us to conclude that the atmosphere above Sofia contained Saharan dust.

\subsection{Results from In Situ $P M_{10}$ Concentration Measurement}

Data provided by the automated measuring stations (AMSs) in Sofia, part of the National Automated System for Environmental Monitoring (NASEM) administrated by the Executive Environment Agency of Bulgaria, ${ }^{57}$ showed high aerosol concentrations at ground level during the Saharan dust events discussed in this work. Five of the stations are located in the city (at 550 to $600 \mathrm{~m} \mathrm{ASL}$ ). In their data, the contribution of anthropogenic aerosols to the mass concentration of particulate matter with an aerodynamic diameter of $<10 \mu \mathrm{m}\left(\mathrm{PM}_{10}\right)$ in winter months is particularly high; we, therefore, did not use these data. The sixth station, Kopitoto AMS, is located at about $800 \mathrm{~m}$ above the other stations (1321 m ASL, 42 $\left.38^{\prime} 13.2^{\prime \prime} \mathrm{N}, 23^{\circ} 14^{\prime} 38.4^{\prime \prime} \mathrm{E}\right)$ in the Vitosha Mountain and is thus classified as an elevated rural reference station for aerosol background measurements. The height of the winter atmospheric boundary layer (ABL) above Sofia is estimated at 900 to $1200 \mathrm{~m}$, so the anthropogenic aerosols contribution to the $\mathrm{PM}_{10}$ data 
Deleva et al.: Lidar study of unusual winter Saharan dust loads above Sofia, Bulgaria: impacts...

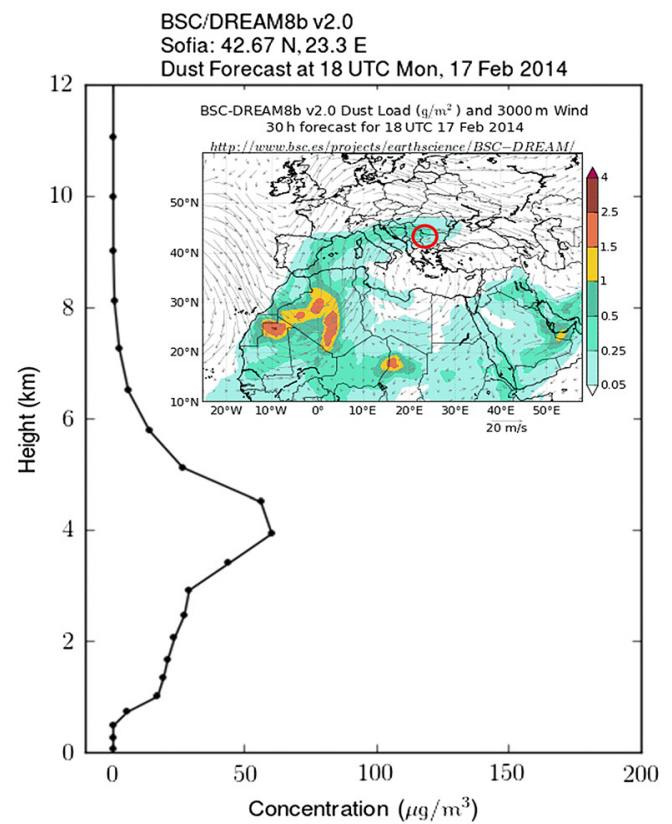

(a)

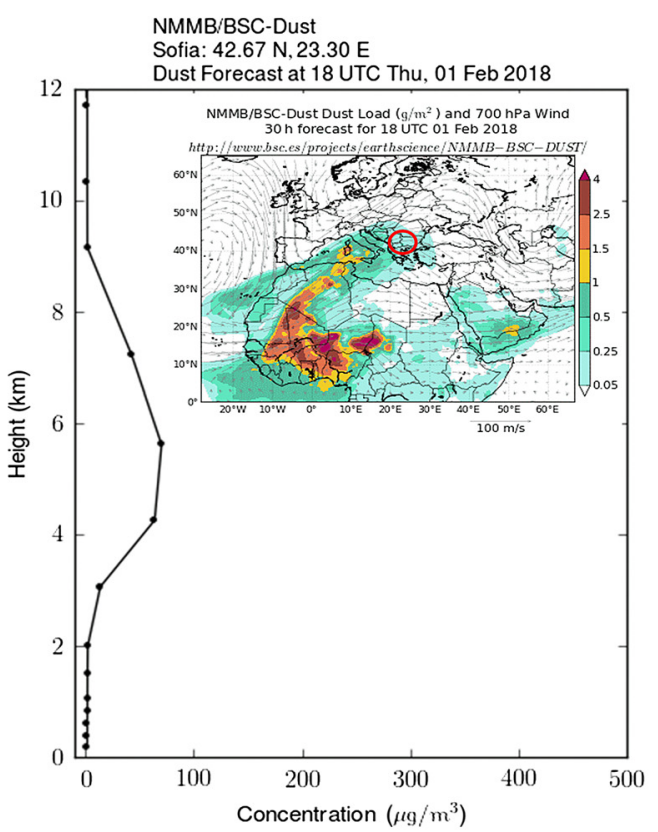

(c)

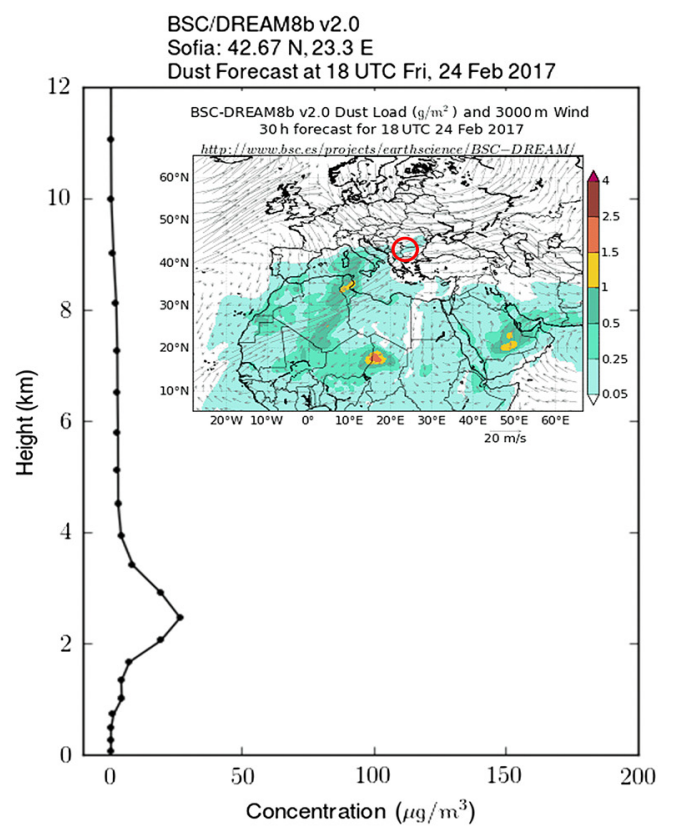

(b)

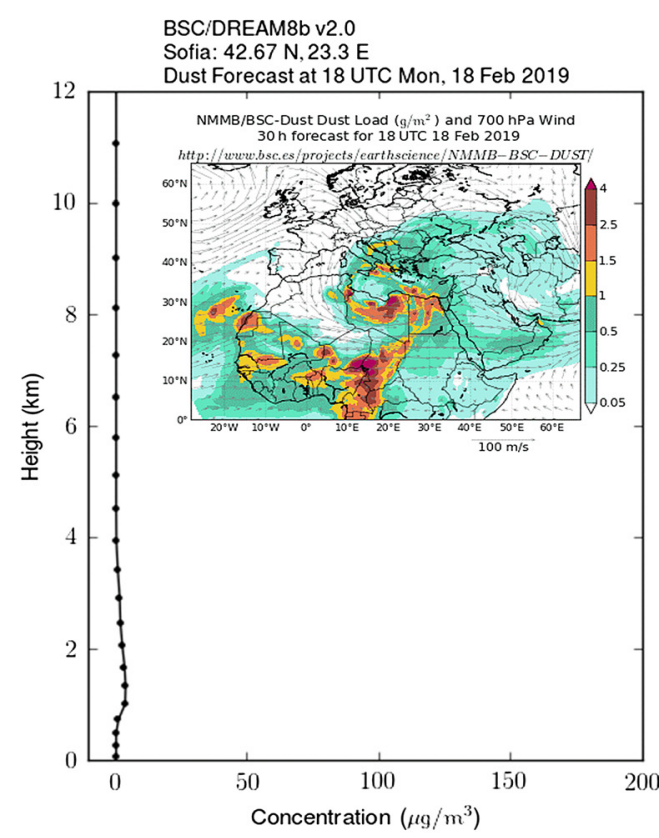

(d)

Fig. 1 BSC-DM forecasted Saharan dust concentration profiles and regional dust load maps (insets) for (a) February 17, 2014; (b) February 24, 2017; (c) February 1, 2018; and (d) February 18, 2019.

provided by this station in wintertime can be neglected. The annual mean values for $\mathrm{PM}_{10}$ registered by this station are $16 \mu \mathrm{g} / \mathrm{m}^{3}$ (2017), $17 \mu \mathrm{g} / \mathrm{m}^{3}$ (2018), and $14 \mu \mathrm{g} / \mathrm{m}^{3}$ (2019).

Time series data of hourly mean values of the $\mathrm{PM}_{10}$ mass concentrations registered by the NASEM AMSs in Sofia, presented in Fig. 2, are available at the European Environment Agency database. ${ }^{58}$ As seen, the hourly mean values of the $\mathrm{PM}_{10}$ mass concentrations at Kopitoto AMS for the periods analyzed here are significantly higher than those normally registered at this station in winter. For instance, the values measured on February 15, 2014, were below $5 \mu \mathrm{g} / \mathrm{m}^{3}$, then increased up to a maximum value of $62 \mu \mathrm{g} / \mathrm{m}^{3}$ at 13:00 LT (11:00 UTC) on 18 February, 


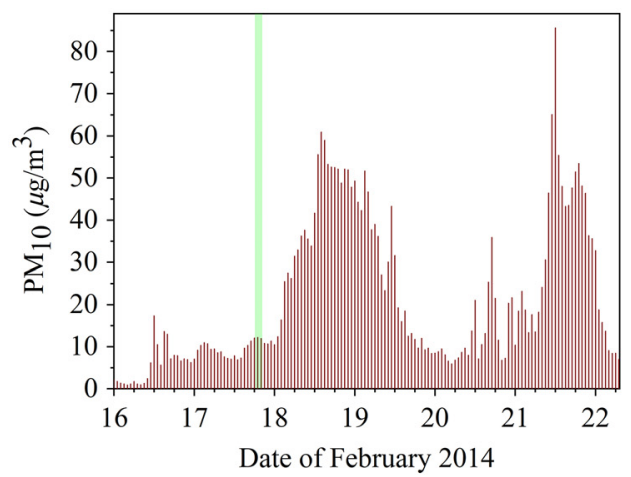

(a)

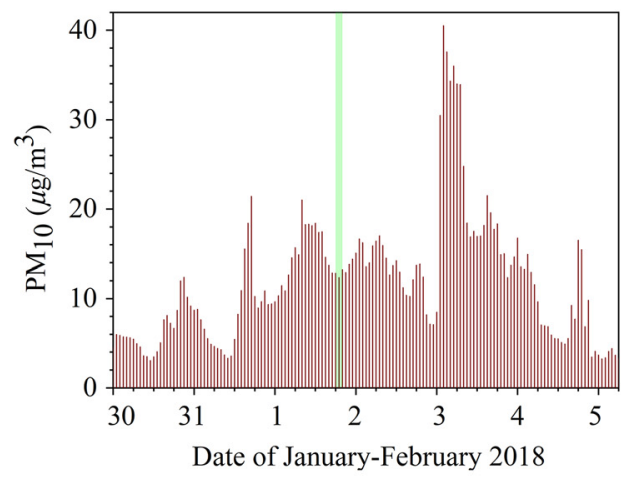

(c)

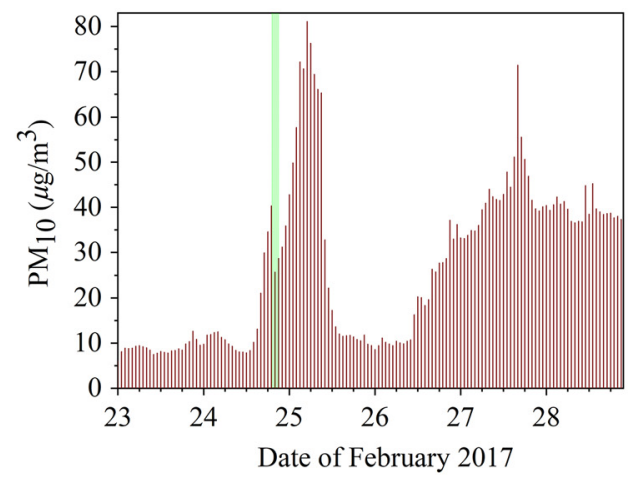

(b)

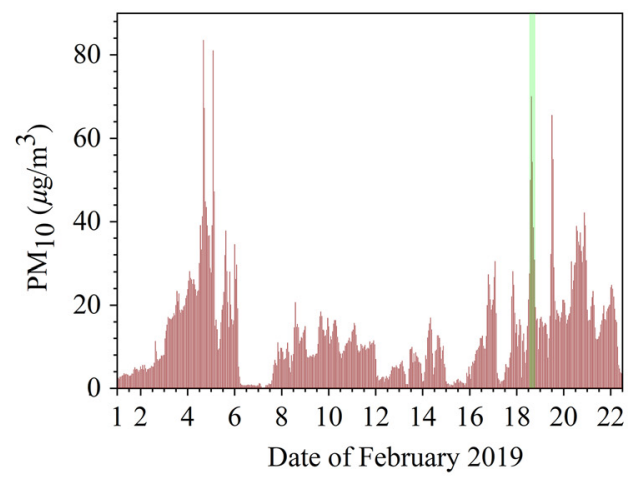

(d)

Fig. 2 Hourly mean values of the $\mathrm{PM}_{10}$ mass concentrations measured by the Kopitoto AMS (BG0070A) in the periods of Saharan dust intrusions over Sofia analyzed in the work: (a) February 16 to 22, 2014; (b) February 23 to 28, 2017; (c) February 1 to 5, 2018; and (d) February 1 to 22, 2019. The vertical green bars indicate the time intervals of lidar measurements.

and decreased slowly reaching values again below $10 \mu \mathrm{g} / \mathrm{m}^{3}$ on 20 February. A similar behavior is seen during the other three transport episodes discussed here.

Juxtaposing the temporal course of $\mathrm{PM}_{10}$ concentration in Fig. 2 to the episodes of Saharan dust transport over Bulgaria listed in Sec. 3.1 demonstrates the good correspondence between these episodes' time intervals and the intervals when increased $\mathrm{PM}_{10}$ concentration was measured over the local ABL. In particular, as can be seen from Fig. 2(d), the aerosol load of the low troposphere over Sofia in the period February 1 to 23, 2019, is high with short breaks, being in good compliance with the BSC-DM forecasts. Therefore, the results of the in situ measurements by the Kopitoto reference AMS confirm the presence of desert dust in the atmosphere above Sofia during the lidar observation described here. It thus becomes possible to use data from this AMS when developing methodologies of calibrating lidar profiles of optical aerosol characteristics with respect to profiles of the mass concentration of atmospheric aerosol when remote lidar sensing is conducted simultaneously with in situ measurements.

\subsection{Air Temperature Composite Anomalies Related to the Dust Load Events Considered}

Figure 3 displays color-coded maps of the air temperature composite anomalies with respect to the climatological means at a 700-mb level over the region of interest for the dates of lidar measurements, based on NCEP/NCAR (National Centers for Environmental Prediction/ National Center for Atmospheric Research) reanalysis of climatological (1981 to 2010) data provided by the NOAA Physical Sciences Laboratory. ${ }^{59}$ As can be seen on the maps, on the days of the lidar measurements considered, Bulgaria is located either in the red areas of the largest positive temperature anomalies reaching values of nearly $10^{\circ} \mathrm{C}$ [panel (a)] or very close 


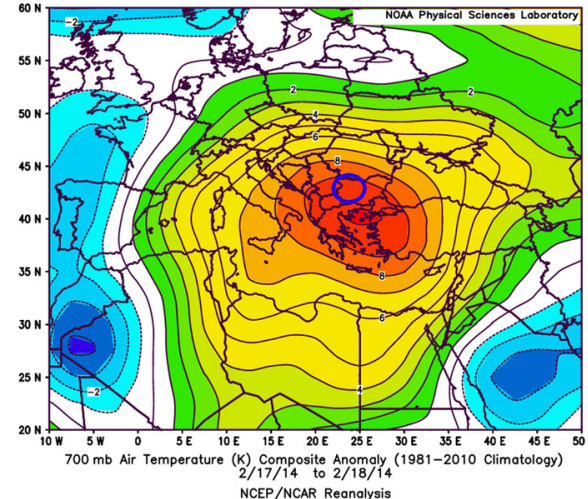

(a)

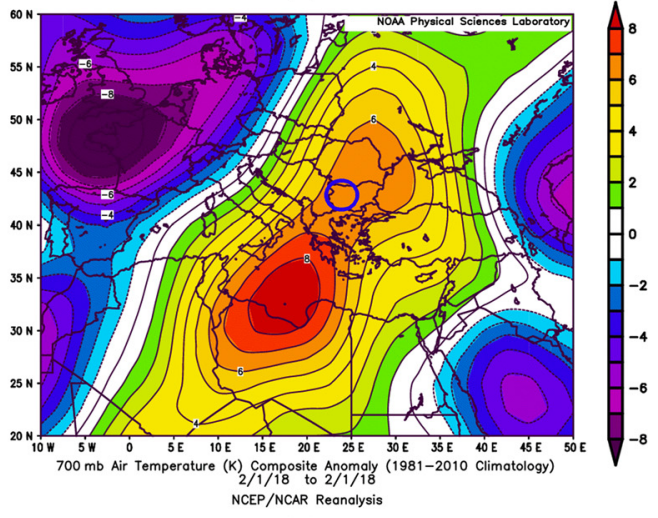

(c)

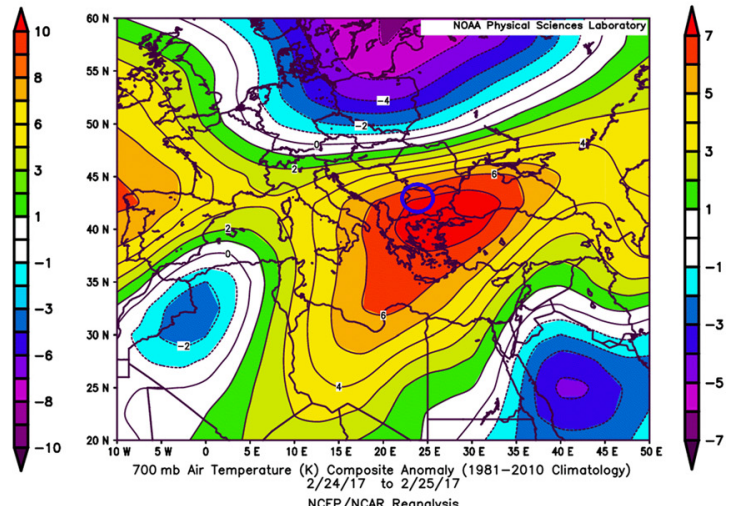

(b)

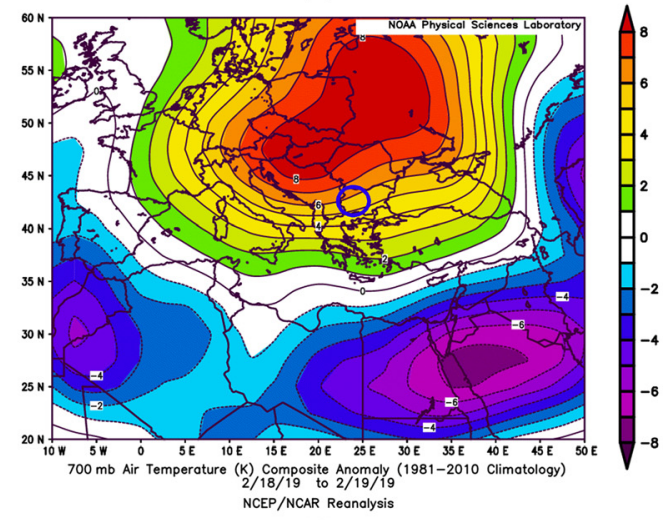

(d)

Fig. 3 Color maps of temperature anomalies at a $700-\mathrm{mb}$ level, with respect to the climatological means for the period 1981 to 2010, over the region North Africa-Mediterranean-Europe, for (a) February 17 and 18, 2014; (b) February 24 and 25, 2017; (c) February 1 and 2, 2018; and (d) February 18 and 19, 2019. The location of Sofia is marked by blue circles.

to them with anomaly values of $6^{\circ} \mathrm{C}$ to $7^{\circ} \mathrm{C}$ [panels (b)-(d)], depending on the stage of the given dust load episode. Referring to case (a), a similar picture and very close values of temperature anomalies for the region of Bulgaria were reported for February 19 and 20, 2014, in Ref. 15.

The color patterns of the temperature anomalies in Figs. 3(a)-3(c) outline well the path of motion of the warm masses carrying desert dust from North Africa drawn mainly to the northeast over the Mediterranean and Europe. We note that these are episodes of active air transport, the core of which has recently reached the region of Bulgaria. In the particular case in Fig. 3(d), there is no such well-defined direction of warm-air transport. Instead, there is a wide oval zone of positive temperature anomalies with the warmest core spread mainly over Central and Northeastern Europe, around which is a vast zone of negative temperature anomalies, including the Sahara Desert. Such a pattern of temperature anomalies indicates a rather completed stage of heat transfer from North Africa to Europe. It agrees well with the finding noted in the Secs. 3.1 and 3.2 that the lidar observation date in question falls at the end of a prolonged dust episode. This is indirectly evidenced by the corresponding histogram of $\mathrm{PM}_{10}$ concentration shown in Fig. 2(d). The maps of the composite temperature anomalies for the entire episodes of desert air/ dust intrusions are similar to those shown in Fig. 3 for the periods close to the lidar measurements performed.

We note that the data on temperature anomalies in Fig. 3 for the region of Sofia are in good agreement with the meteorological radiosonde data related to the near ground air temperature in the days of lidar measurements, presented in the Secs. 5.1.1-5.1.4. Together, they testify to the strong and direct perturbing effects of the warm air masses and desert dust transport from North Africa on such an important component of local weather as the air temperature. 


\section{Aerosol Layering Structure and Air Mass Transport Forecasts}

The atmospheric aerosol loads registered during four-day lidar observations conducted at the wavelength of $1064 \mathrm{~nm}$ analyzed here are presented in Figs. 4-7 as RCS colormaps in height-time coordinates to illustrate the temporal evolution of the aerosol height distribution. The respective HYSPLIT diagrams depict the backward air mass trajectories, which provide insight into how the air masses over Sofia (during the lidar sensing) had been moving a few days before the measurement. They include three trajectories that end over Sofia at heights falling within characteristic height sections of the retrieved profile of the atmospheric aerosol BSC. The information provided by the BSC-DM and HYSPLIT models is used to draw conclusions concerning the origin and type of the particles in the aerosol layers registered.

Figure 4(a) shows a dynamic colormap displaying the temporal evolution of the aerosol height distribution during the lidar measurements conducted on February 17, 2014. In Fig. 4(b),

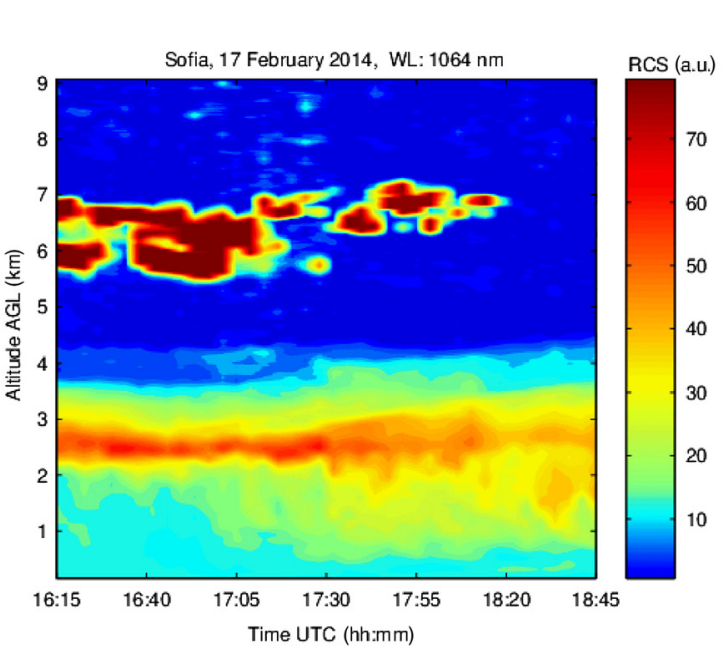

(a)

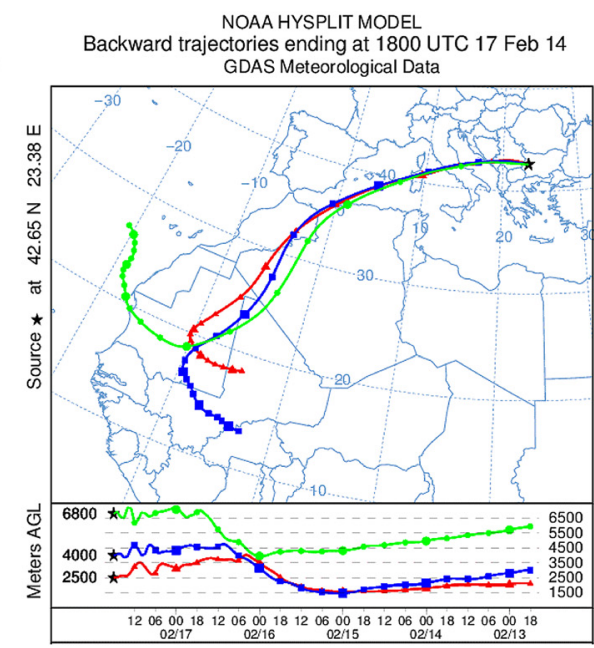

(b)

Fig. 4 (a) Time series of the dust/aerosol vertical distribution in terms of range-corrected lidar signals, as measured on February 17, 2014, at $1064 \mathrm{~nm}$ and (b) HYSPLIT-model backward trajectories ending above Sofia at 18:00 UTC on the same day.

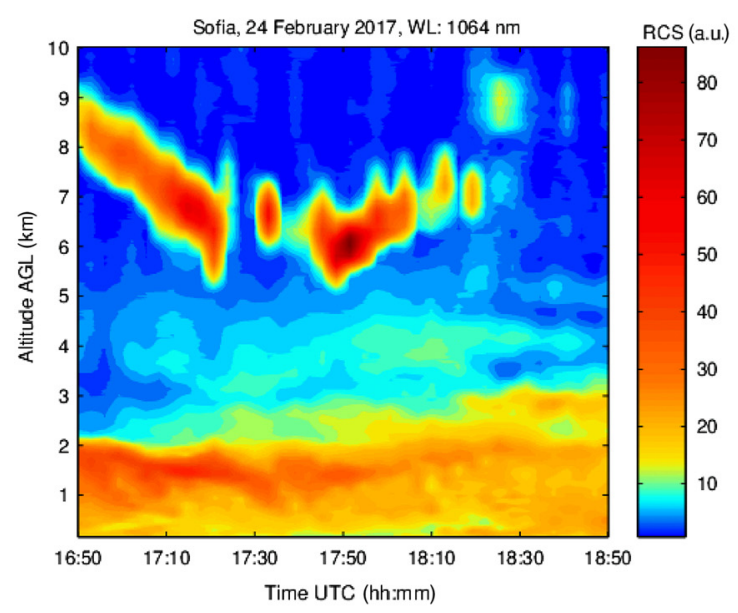

(a)

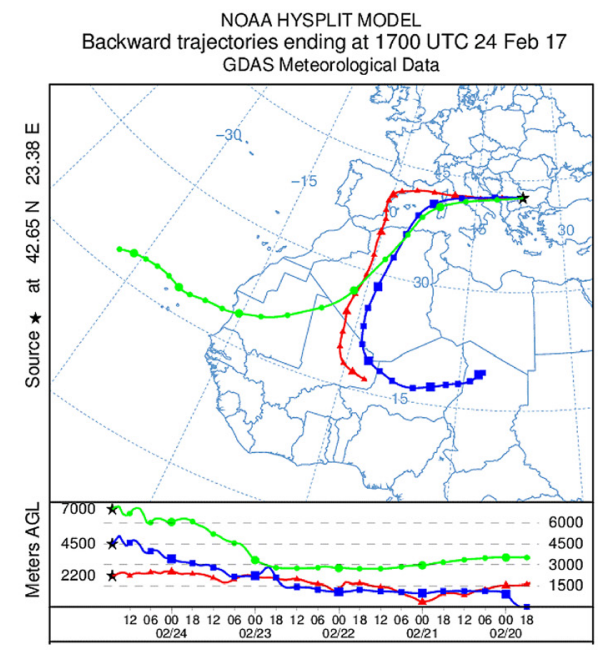

(b)

Fig. 5 (a) Time series of the dust/aerosol vertical distribution in terms of range-corrected lidar signals, as measured on February 24, 2017, at $1064 \mathrm{~nm}$ and (b) HYSPLIT-model backward trajectories ending above Sofia at 17:00 UTC on the same day. 


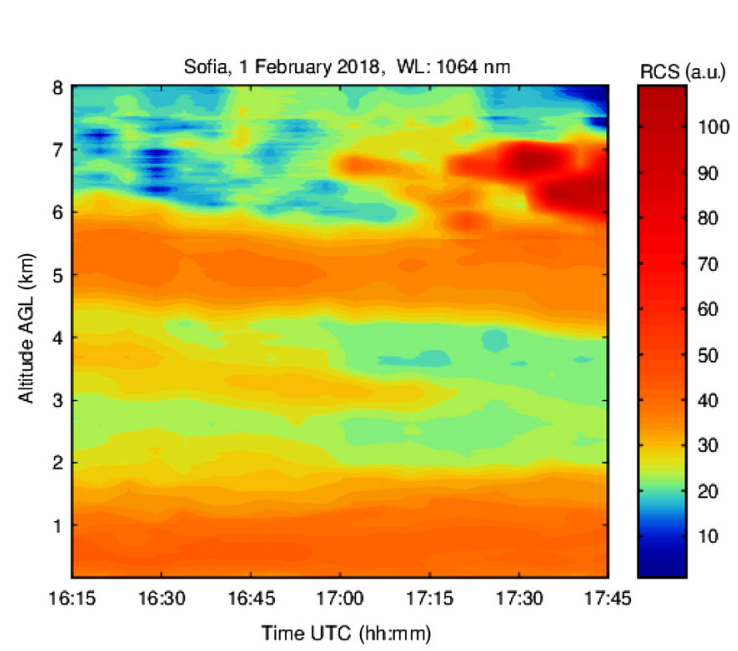

(a)

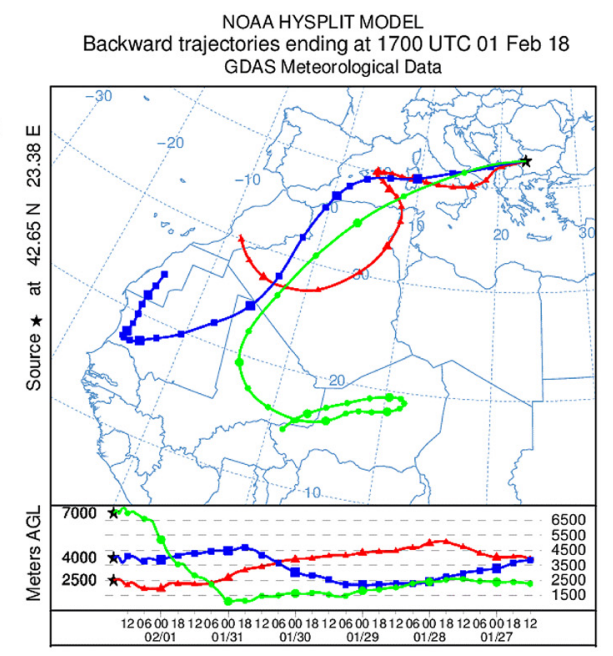

(b)

Fig. 6 (a) Time series of the dust/aerosol vertical distribution in terms of range-corrected lidar signals, as measured on February 1, 2018, at $1064 \mathrm{~nm}$ and (b) HYSPLIT-model backward trajectories ending above Sofia at 17:00 UTC on the same day.

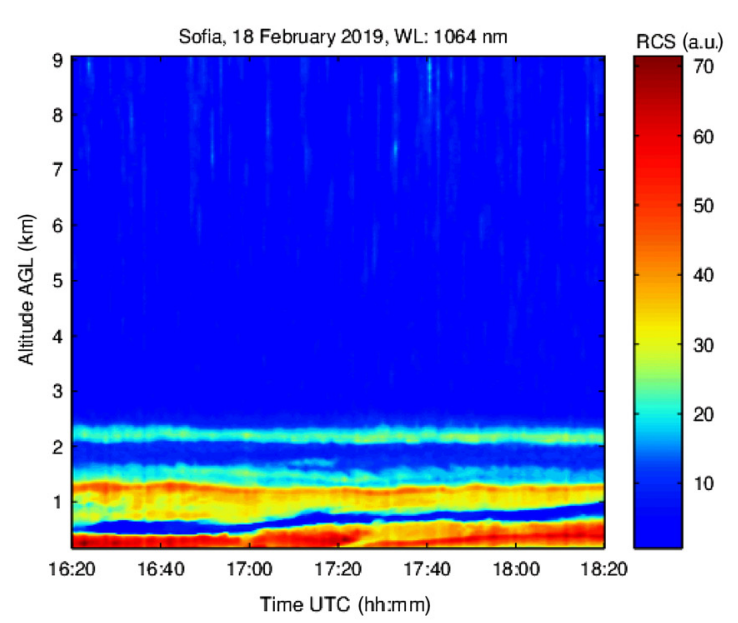

(a)

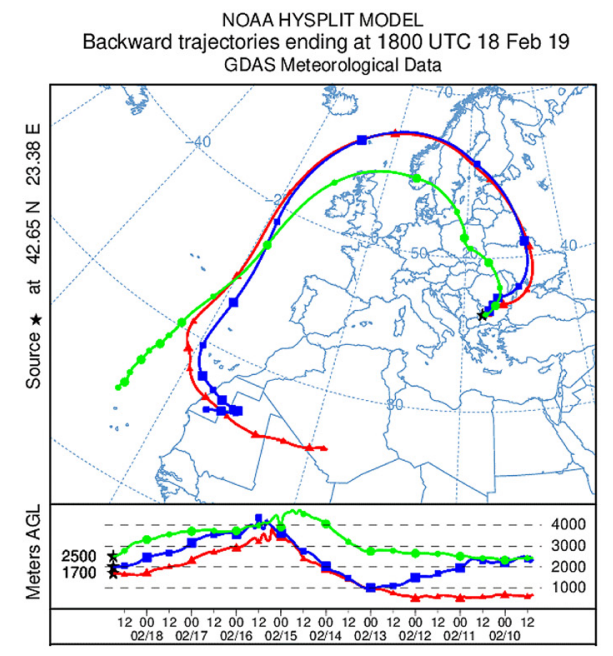

(b)

Fig. 7 (a) Time series of the dust/aerosol vertical distribution in terms of range-corrected lidar signals, as measured on February 18, 2019, at $1064 \mathrm{~nm}$ and (b) HYSPLIT-model backward trajectories ending above Sofia at 18:00 UTC on the same day.

the HYSPLIT backward trajectories calculated for the time interval of the lidar observations are shown. As seen, on that day, the lidar registered an aerosol layer extending from the ground to $4.5 \mathrm{~km}$ and another one with a variable structure in the 5.8- to 7-km range, most probably a cirrus cloud. The lower layer includes a clearly delineated dense part ( 2 to $3 \mathrm{~km}$ ), which during the measurements undergoes a partial downward redistribution of the aerosol density.

The trajectories for heights 2.5 to $4 \mathrm{~km}$ (120-h duration) indicate that the air masses in this height range have moved for a long time low over the Sahara surface. The trajectory terminating over Sofia at $6.8 \mathrm{~km}$ shows that the air masses originating from the Atlantic Ocean have passed over the Sahara in the height range 4.5 to $5.5 \mathrm{~km}$, thus remaining within the Saharan ABL, the upper boundary of which reaches 5 to $6 \mathrm{~km} .{ }^{60-62}$ One can, therefore, assume with a high probability that the air masses at $6.8 \mathrm{~km}$ above Sofia have transported dust from the Sahara Desert. 
In summary, the evidence supplied by the above HYSPLIT backward trajectories combined with the BSC-DM forecasted profile in Fig. 1(a) lead us to the conclusion that on February 17, 2014, the atmospheric aerosols detected above Sofia within the height range 1 to $6.5 \mathrm{~km}$ consisted predominantly of desert aerosols transported over a long distance, their highest mass concentration being at 2 to $3 \mathrm{~km}$. Also these data provide grounds to presume that the formation of the cirrus cloud seen in the height range 5.8 to $7 \mathrm{~km}$ was assisted by the desert particles serving as condensation nuclei.

Figure 5(a) shows an RCS map constructed using vertical lidar profiles recorded on February 24,2017 . The altitude range of the RCS dynamic colormap shown is limited to $10 \mathrm{~km}$, as the atmosphere above was free of aerosols. However, below this limit, practically the whole troposphere was loaded with varying amounts of aerosols. One can see a quite dense and wellexpressed aerosol layer located between the surface and altitudes of 2 to $2.7 \mathrm{~km}$, randomly extended up to nearly $5 \mathrm{~km}$ with a decreasing density. Above it, relatively dense aerosol layers occur with a "wings"-like distribution in the range 5 to $9 \mathrm{~km}$. In this height range, cirrus clouds normally appear, which most probably is also the case here.

Figure 5(b) shows the HYSPLIT-model backward trajectories ending at 17:00 UTC on February 24, 2017, above Sofia at heights of 2.2, 4.5, and $7 \mathrm{~km}$, calculated for a 120-h period. One can see that all trajectories have parts passing over the Sahara Desert for considerable time periods (1.5 to 3 days). At the two lower altitudes, the air masses moved through the Sahara ABL near the desert surface, thus possibly capturing considerable amounts of mineral dust. It is worth noting that during the days prior to the measurements, according to BSC-DM forecasts, the lower atmosphere over the Sahara regions considered had been rich in very dense dust fields, enabling dust transport to the site of lidar measurements. The trajectory ending at $7 \mathrm{~km}$ passed over the Atlantic Ocean and relatively high over the Sahara (at a height of $3 \mathrm{~km}$, but within the desert ABL). Therefore, most likely the air masses at the height of $7 \mathrm{~km}$ above Sofia during the measurements contained moisture and desert aerosols, which could serve as condensation nuclei for the formation of the cirrus clouds registered.

Based on the modeling presented above and the preprocessed lidar data, one can convincingly state that the atmospheric domains from the surface up to altitudes of about $5 \mathrm{~km}$ in the time interval of lidar measurements conducted on February 24, 2017, contained considerable amounts of Saharan-dust-rich aerosols, whereas the aloft aerosol layers above $5 \mathrm{~km}$ were most probably cirrus clouds.

Figure 6 shows the RCS time series obtained on February 1, 2018, and selected HYSPLIT trajectories, in support of the conclusions drawn about the origin of the lidar-registered aerosols. The colormap illustrates the temporal evolution of the aerosol height distribution in the time interval 16:15 to 17:45 UTC. The altitude range is limited to $8 \mathrm{~km}$ because the atmosphere above was free of aerosols. As seen in Fig. 6(a), two zones differing in their vertical mass stratification can be distinguished for the time interval of the experiment. The first one occurs between 16:15 and 17:15 UTC, and the second occurs between 17:15 and 17:45 UTC. During the first hour of sounding, a well-defined layered structure can be demarcated in the aerosol field observed, with three characteristic height zones of aerosol loading. Thus a bottom aerosol layer of relatively high density extends from the surface up to $2 \mathrm{~km}$. Above it, two partially merged layers are situated-one in the range 3 to $4 \mathrm{~km}$ and another one of higher density and homogeneity in the range 4.8 to $6 \mathrm{~km}$. The second time interval is characterized by changes in the aerosol field structure. In particular, the intermediate aerosol layer ( 3 to $4 \mathrm{~km}$ ) has dissipated, whereas a denser and inhomogeneous layer has appeared between 6 and $7 \mathrm{~km}$.

The HYSPLIT-model backward trajectories (calculated for a 130-h period) ending above Sofia at heights 2.5 to $7 \mathrm{~km}$ [Fig. 6(b)] indicate that the air masses have drifted for a long period of time over the Sahara Desert passing through its ABL. Therefore, it could be expected that the aerosol layers in this height range above Sofia contain Saharan dust.

Figure 7 exhibits information related to the measurement conducted on February 18, 2019. The results of this lidar observation differ from those discussed so far by the detection of a clearly outlined narrow aerosol layer over the ABL between 2.1 and $2.4 \mathrm{~km}$, above which the atmosphere is clear [Fig. 7(a)]. Below this layer, the aerosol mass is distributed in two other distinct layers-a denser one near the ground and one of lower density centered around the height of $1 \mathrm{~km}$. 
The backward trajectories for February 18, 2019, shown in Fig. 7(b), combined with the BSC-DM maps for the same day [Fig. 1(d)] and several days earlier, provide evidence for the presence of considerable amounts of Saharan dust in the two upper aerosol layers registered (in the height range 0.5 to $2.5 \mathrm{~km}$ ) captured partially directly over the Sahara and partially indirectly from regions with an atmosphere rich in desert dust.

\section{Lidar Profiling of Aerosol Properties}

\subsection{Vertical Lidar Profiling of Aerosol Density and Backscatter-Related Ångström Exponent Analysis}

In the following sections, we present and analyze separately for each measurement the averaged vertical profiles of the aerosol BSC calculated for the two laser wavelengths and the corresponding Ångström exponent profile. The conclusions about the origin and composition of the registered aerosol layers are supported by HYSPLIT and BSC-DM modeling data as well as by meteorological radiosonde data.

\subsubsection{Lidar observations conducted on February 17, 2014}

Figure 8 presents vertical profiles up to a height of $9 \mathrm{~km}$ of the atmospheric aerosols' optical and microphysical parameters derived from data of lidar measurements carried out in the interval 14:20-16:40 UTC on February 17, 2014, as well as meteorological profiles for the same day.

The retrieved height profiles of the aerosol BSC for the two lidar wavelengths $(1064 / 532 \mathrm{~nm})$ averaged over the entire measurement period are shown in Fig. 8(a). The graphs are displayed starting from the initial height of $0.35 \mathrm{~km}$, where the laser beam and the receiving telescope field of view overlap completely. The profiles consist of two main thick layers: a low relatively smooth aerosol/dust layer extending up to a height of $4.5 \mathrm{~km}$ with a maximum at about $3.6 \mathrm{~km}$ and a layer of cirrus clouds in the range of 5.5 to $7.5 \mathrm{~km}$ with a more complex shape. This structure is an integral variant of the aerosol distribution map shown in Fig. 4(a) for the day in question.

The maximum aerosol BSC values for the bottom layer are $8.08 \mathrm{Mm}^{-1} \mathrm{sr}^{-1}$ at $532 \mathrm{~nm}$ and $5.14 \mathrm{Mm}^{-1} \mathrm{sr}^{-1}$ at $1064 \mathrm{~nm}$. These values are significantly higher (about 3 to 4 times) than the ones measured most frequently at ABL heights in the Sofia area, which is indicative of

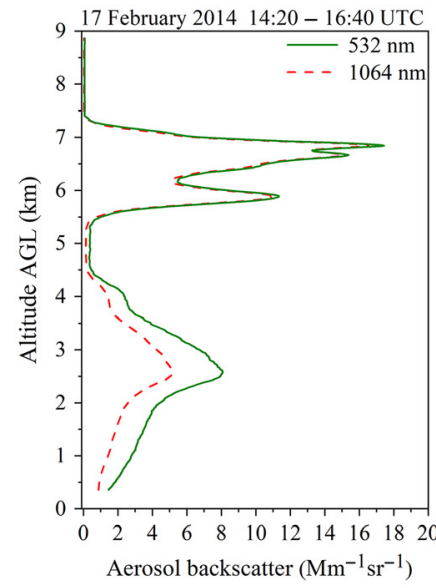

(a)

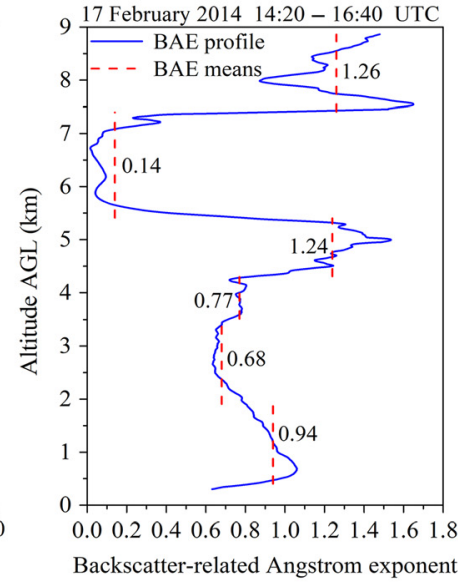

(b)

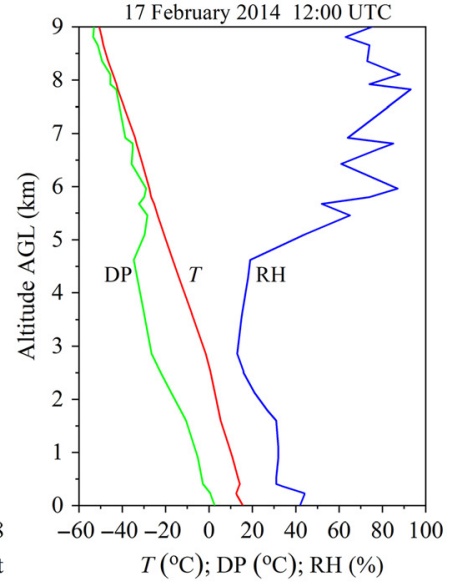

(c)

Fig. 8 Lidar measurements carried out on February 17, 2014: (a) vertical profiles of the aerosol BSC at the two laser wavelengths 532 and $1064 \mathrm{~nm}$. (b) The corresponding aerosol BAE derived from the lidar measurements. Mean BAE values of characteristic profile parts are labeled and shown by dashed lines. (c) Meteorological radiosonde data (temperature, $T$; dew point, DP; and relative humidity, $\mathrm{RH})$. 
a significant amount of aerosol load. Bearing in mind the BSC-DM forecast map in Fig. 1(a) and the HYSPLIT backward trajectories shown in Fig. 4(b), one can state with certainty that the dense unstructured layer observed up to $4.5 \mathrm{~km}$ is composed mainly of Saharan dust. This conclusion is indirectly supported by the BSC-DM-forecasted height profile of the concentration of Saharan dust over Sofia in Fig. 1(a) related to the time of lidar measurements, which is similar in terms of height location and shape to the BSC ones.

Figure 8(b) shows the vertical profile of the BAE obtained on the basis of the BSC profiles seen in Fig. 8(a) as well as the average BAE values for several characteristic height intervals from this profile. In the densest central section of the dust layer ( 2 to $3.5 \mathrm{~km}$ ), the average BAE value is 0.68 , in the sublayer above it ( 3.5 to $4.3 \mathrm{~km})$ it is 0.77 , and in the lower part of the layer $(0.5$ to $2 \mathrm{~km}$ ) located in and just above the ABL it is 0.94 . The corresponding backward trajectories in Fig. 4(b), significant portions of which extend over the Sahara Desert passing around the middle of its ABL, clearly point to desert aerosol content in these layers. Therefore, the BAE values determined for the central and upper part of the dust layer (0.68 and 0.77 , respectively) can be considered to be related to the inflowing dust-containing aerosols. The one for the lower part of the layer (0.94) is likely characterizing the mix of dust with aerosols (apparently finer ones) of local origin present over the Sofia region. Note that BAE values of about 0.7 indicate the predominant presence of dust fractions of micron- and slightly-over-micron- size ranges. ${ }^{63}$ This may be related to the fact that the corresponding backward trajectories do not pass near the desert surface but mainly through the ABL above it.

Near-zero BAE values in the height range of cirrus clouds (5.5 to $7.5 \mathrm{~km}$ ) with an average value of 0.14 are typical for this type of cloud composed of large ice crystals.$^{64}$ In the aerosol-free zones below $(4.5$ to $5.5 \mathrm{~km})$ and above $(>7.5 \mathrm{~km})$ the cirrus clouds, the BAE exhibits values of about 1.25 that are common for background aerosols in the free troposphere. Therefore, these standard values in the above two cases indirectly support and validate the BAE values obtained for the aerosol layers dominated by Saharan dust.

The intrusions of warm air masses carrying desert aerosols over the Sofia region in February, which were uncharacteristic in the near past as this is one of the coldest winter months in Bulgaria, should be expected to perturb the weather and the atmospheric parameters in the region. Figure 8(c) shows the vertical profiles of the atmospheric temperature $(T)$, dew point (DP), and relative humidity (RH) obtained by radiosonde on February 17, 2014. A good correspondence can be found between the meteorological profiles presented and the BSC ones displayed in Fig. 8(a). Near the surface, the air temperature has atypical values for the season at about $15^{\circ} \mathrm{C}$, being consistent with the composite temperature anomalies shown in Fig. 3(a). In the lower zone below $4.5 \mathrm{~km}$ where the Saharan dust layer is located, the RH appears to be very low (20\% to 30\%). Expectedly, the DP profile is very well separated from the $T$ one, reflecting the extremely dry conditions far from those for water condensation. The minimum of the RH profile is almost exactly at the same height as the maximum of the Saharan dust layer. Within the cirrus cloud height range, a quite high RH value of about $80 \%$ is measured, whereas the DP profile is tightly approaching the $T$ one. The aerosol-free zone $(4.5$ to $5.5 \mathrm{~km})$ appears to be a transitional one, connecting the markedly dry lower part and the considerably more humid upper part of the profiles.

The above-mentioned features of the meteorological profiles, being in good accordance with the presence, concentration, and distribution of desert aerosols, can be regarded as convincing evidence of the serious impact that the atypical incursions for the winter season of Saharan dustcontaining warm air masses have on the local meteorological conditions and parameters.

\subsubsection{Lidar observations conducted on February 24, 2017}

Figure 9 presents vertical profiles up to a height of $10 \mathrm{~km}$ of the atmospheric aerosols' optical and microphysical parameters from lidar measurements carried out in the interval 16:50 to 18:50 UTC on February 24, 2017, and the meteorological profiles for that day.

Time-averaged height profiles of the aerosol BSC retrieved for the two lidar wavelengths are displayed in Fig. 9(a). Based on the analysis of the air-transport modeling data presented above, the BSC profiles obtained can be divided in two main parts: a lower part extending up to altitudes of about $5.5 \mathrm{~km}$ containing aerosols dominated by Saharan dust and an upper part in the altitude 
Deleva et al.: Lidar study of unusual winter Saharan dust loads above Sofia, Bulgaria: impacts...

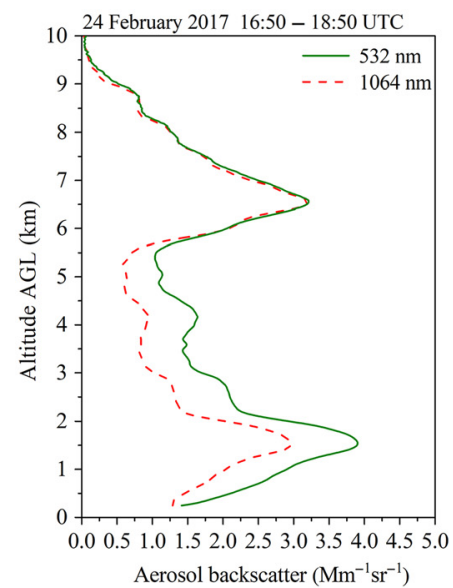

(a)

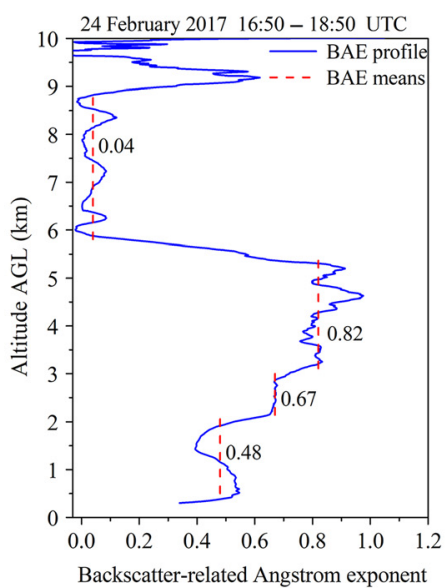

(b)

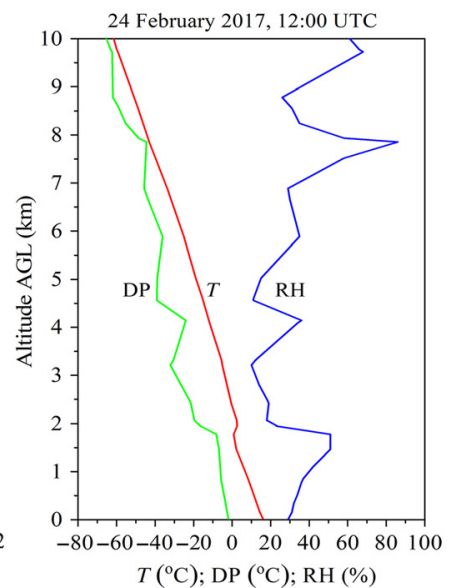

(c)

Fig. 9 Lidar measurements carried out on February 24, 2017: (a) vertical profiles of the aerosol BSC at the two laser wavelengths 532 and $1064 \mathrm{~nm}$. (b) The corresponding aerosol BAE derived from the lidar measurements. Mean BAE values of characteristic profile parts are labeled and shown by dashed lines. (c) Meteorological radiosonde data (temperature, $T$; dew point, DP; and relative humidity, $\mathrm{RH})$.

range 5.5 to $10 \mathrm{~km}$ consisting of cirrus clouds. The strongly pronounced bottom of the lower part, stretching up to about $3.5 \mathrm{~km}$ and centered at an altitude of $1.5 \mathrm{~km}$, correlates very well with the BSC-DM dust concentration profile for the time of lidar measurements, displayed in Fig. 1(b). The BSC profiles at the two wavelengths show a gradual decrease in the aerosol density upward to $5.5 \mathrm{~km}$, with some secondary bulges centered close to 2.8 and $4.2 \mathrm{~km}$. The more distinct sublayer in the height range 3.5 to $5.0 \mathrm{~km}$ and centered at about $4.2 \mathrm{~km}$ is also identified as containing mainly desert aerosols based on the HYSPLIT backward trajectories shown in Fig. 5(b).

The peak values of the aerosol BSC in the lower dust-dominated part of the profiles are calculated to be of $2.95 \mathrm{Mm}^{-1} \mathrm{sr}^{-1}$ at $1064 \mathrm{~nm}$ and $3.91 \mathrm{Mm}^{-1} \mathrm{sr}^{-1}$ at $532 \mathrm{~nm}$. These values are about two times lower than the ones obtained on February 17, 2014, but they are still significantly higher than those usually measured for general aerosols at ABL altitudes above Sofia. Therefore, this particular event of Saharan dust load can be classified as a moderate-to-strong one. Note that this particular date of lidar measurements is the first one of a four-day dust intrusion episode. Typically for the beginning of dust load events, aloft cirrus clouds are present, extending within a height range of about $5 \mathrm{~km}$ above the dust-containing layers.

Moving upward, the color ratio (defined as $\mathrm{BSC}_{532} / \mathrm{BSC}_{1064}$ ) exhibits an emerging tendency to increase. However, above $6 \mathrm{~km}$, the BSC profiles at 1064 and $532 \mathrm{~nm}$ rapidly approach each other to nearly merge along the whole cirrus cloud altitude range, reaching the peak value of $3.2 \mathrm{Mm}^{-1} \mathrm{sr}^{-1}$ at an altitude of $6.6 \mathrm{~km}$.

According to the BSC-DM forecasts, two other short Saharan dust load events took place above Sofia in the beginning of February 2017, one of which (on 6 February) was also detected by our lidar.

The vertical BAE profile calculated based on the discussed above BSC profiles at the two lidar wavelengths is displayed in Fig. 9(b) to analyze and characterize qualitatively the microphysical properties of the detected aerosols in terms of size fraction domination. As previously adopted, the mean BAE values for the distinguished sublayers are denoted by vertical dashed lines.

As can be seen in the lower part of Fig. 9(b), the BAE values increase in the upward direction in the range 0.4 to $1.0 \mathrm{~km}$ in a nearly stepwise manner with the altitude changing from 1 to $6 \mathrm{~km}$, following the above-mentioned increase of the color ratio. Taking into account the inverse proportion between the BAE values and the dominant size of the aerosol particles, the conclusion could be drawn that the obtained BAE profile reveals some stratification of the dust particle size fractions, with the coarser modes located at the bottom of the layer and the finer ones located 
near its top. At an altitude of $1.5 \mathrm{~km}$ corresponding to the peak of the bottom aerosol layer, the $\mathrm{BAE}$ reach its minimum value of 0.4 , indicating the largest dust particle modes. In general, such stratification is considered natural, resulting from processes of gravitational settling or similar aerosol/dust sedimentation processes.$^{65}$ The obtained BAE values correspond approximately to dominating dust particle size in the near over-micron range. ${ }^{33}$ In contrast, the BAE values in the altitude range above $6 \mathrm{~km}$ steeply decrease, keeping levels close to zero, being typical for cirrus clouds. ${ }^{8,33,66}$ We regard them as reference ones, indirectly supporting the validity and reliability of the obtained BSC and BAE profiles.

Meteorological radiosonde data are shown in Fig. 9(c) to assist the analysis of the effects of desert aerosols on the state and conditions of the atmosphere above Sofia, as well as to clarify their distribution and interactions with local aerosols. The vertical profiles of the atmospheric $T$, $\mathrm{DP}$, and $\mathrm{RH}$ are displayed for altitudes up to $10 \mathrm{~km}$. Within the dust-dominated height range up to $6 \mathrm{~km}$, the RH expectedly exhibits low values in the range $10 \%$ to $50 \%$. A thermal inversion is observed on the $T$ profile in the altitude range 1.8 to $2.1 \mathrm{~km}$. The aerosols are normally confined below the inversion, with the latter serving as a barrier preventing the upward penetration of particulate matter. To some extent, such an effect can be observed by referring to Fig. 9(a), which shows that the densest bottom aerosol layer is almost entirely concentrated immediately below the inversion. However, aerosol layers are also continuously extending far above the inversion. This means that the desert aerosols breaking through the inversion barrier are most likely present both above and below it, thus mixing with local aerosols, including ABL ones.

As seen in Fig. 9(c), the temperature at the surface is approaching $20^{\circ} \mathrm{C}$, which is unusually high for the month of February in Bulgaria. This is in good agreement with the picture of the composite temperature anomaly for the day shown in Fig. 3(b). Moreover, referring to the RH and DP profiles, an evident drying of the atmospheric air can be observed above the inversion in the altitude range 2 to $5.5 \mathrm{~km}$. These peculiarities witness to the significant heat transfer from North Africa to the Sofia region taking place in the middle of the winter season, which can naturally be attributed to the Saharan dust load event. The DP profile touches the $T$ one at an altitude of $7.8 \mathrm{~km}$, indicating favorable conditions for the crystal nucleation process forming the cirrus clouds. However, this is about $1.2 \mathrm{~km}$ above the peak of the observed cirrus clouds, as can be seen in Fig. 9(a). This deviation can be ascribed to the gap between the time of meteorological radiosonde measurements (12:00 UTC) and the one of lidar measurements (16:50 to 18:50 UTC). More specifically, this can result from the diurnal downward convection of the atmospheric air in the evening hours (particularly after sunset at 15:13 UTC).

\subsubsection{Lidar observations conducted on February 1, 2018}

Figure 10 presents vertical profiles, up to a height of $8 \mathrm{~km}$, of optical and microphysical parameters of atmospheric aerosols from lidar measurements carried out in the interval 16:15 to 17:45 UTC on February 1, 2018, as well as meteorological profiles for that day. Representative timeaveraged height profiles of the aerosol BSC for the two lidar wavelengths $(1064 / 532 \mathrm{~nm})$ are shown in Fig. 10(a). Referring to the BSC-DM modeling data about the vertical distribution of dust concentration in Fig. 1(c), as well as to a more extensive analysis of the HYSPLIT backward trajectories including the ones displayed in Fig. 6(b) and discussed above, one can conclude that on February 1, 2018, desert aerosols were present in the atmosphere above Sofia mainly in the height range 2.5 to $7.5 \mathrm{~km}$. According to the BSC-DM forecasts, Saharan dust load events with an overall duration of nine days occurred above Sofia in the first half of February 2018, indicating moderate to high-dust transport activity in the considered winter period.

At the bottom of the BSC profiles in Fig. 10(a), a well-outlined layer occurs located mostly within the local ABL and slightly above its seasonal top. It is identified to be mainly consisting of local aerosols. Moving upward, the BSC profiles at the two wavelengths reveal the thick dustcontaining layer mentioned above, consisting of a pronounced main aerosol layer centered at about 5.0 to $5.5 \mathrm{~km}$ and secondary layers of lesser density below and above located in the altitude ranges 2.5 to $4 \mathrm{~km}$ and 6.5 to $7.5 \mathrm{~km}$, respectively. This layer structure is a time-averaged expression of the one appearing in the already commented on dynamical colormap shown in Fig. 6(a). The BSC peak values for the densest dust-containing layer are $0.87 \mathrm{Mm}^{-1} \mathrm{sr}^{-1}$ for $532 \mathrm{~nm}$ and $0.63 \mathrm{Mm}^{-1} \mathrm{sr}^{-1}$ for $1064 \mathrm{~nm}$, i.e., considerably lower than the ones obtained in the two 


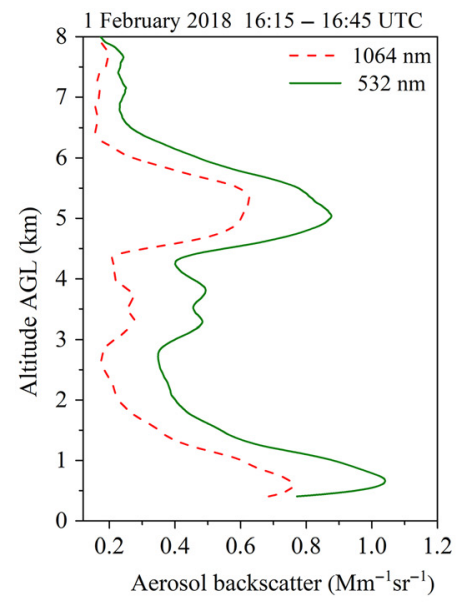

(a)

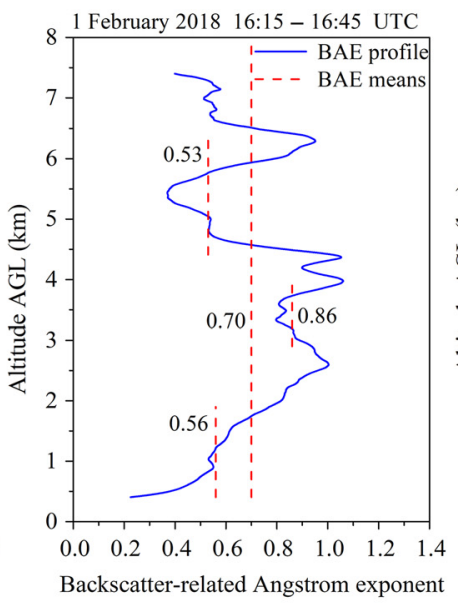

(b)

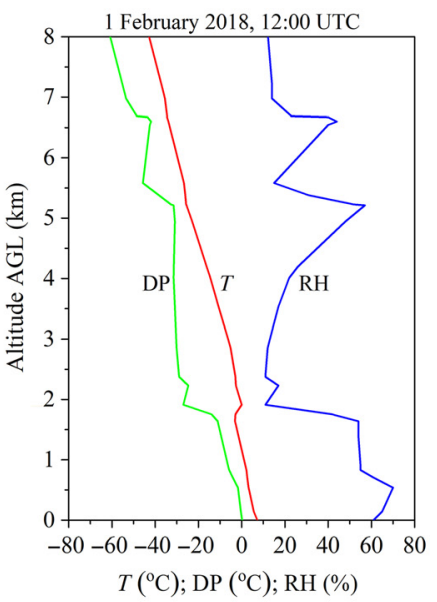

(c)

Fig. 10 Lidar measurements carried out on February 1, 2018: (a) vertical profiles of the aerosol BSC at the two laser wavelengths 532 and $1064 \mathrm{~nm}$. (b) The corresponding aerosol BAE derived from the lidar measurements. Mean BAE values of characteristic profile parts are labeled and shown by dashed lines. (c) Meteorological radiosonde data (temperature, $T$; dew point, DP; and relative humidity, $\mathrm{RH})$.

previously considered cases. These low BSC values can be ascribed to the above-mentioned extension of the total dust-containing aerosol field over a quite wider height range, as well as to the absence of significant amounts of other aerosols to be mixed with, in contrast to the preceding cases.

Figure 10(b) shows the BAE vertical profile corresponding to the BSC profiles in Fig. 10(a). The average BAE values for the entire height interval shown, as well as for the several characteristic aerosol layers from the BSC profiles, particularly, those comprising dust, are again marked by vertical dashed lines. The mean BAE value averaged over the whole profile range is calculated to be of $0.70 \pm 0.24$, thus falling into the range commonly obtained for dust-dominated aerosols in the Sofia region. ${ }^{8,12}$ The aerosol layer located close to the surface in the height range 0.4 to $1.8 \mathrm{~km}$ exhibits increasing in the upward direction BAE values from 0.25 to 0.70 with a mean of 0.56 , indicating domination of coarser-particle size modes. The BAE values typical for aerosols within the ABL over Sofia are normally in the range 1 to 2 . We consider two likely reasons for these lower BAEs. The first one is associated with the possible penetration of coarse fractions of Saharan dust into the local ABL, in accordance with the BSC-DM profile of the dust concentration vertical distribution in Fig. 1(c). The second one is related to the fact that in the winter period the atmospheric layer adjacent to the surface is normally rich in soot originating from residential heating. In the height range 3 to $4 \mathrm{~km}$, where the twin-peak dust layer of relatively low density is present, the BAE assumes values in the range 0.8 to 1.0 with a mean of 0.86 , indicating dust particles of a moderate size without strong domination of coarse or fine size modes. Further upward, in the altitude range of the densest dust layer (4.3 to $6.4 \mathrm{~km}$ ), BAE values drop to reach a minimum level of about 0.35 , pointing to the presence of significantly coarser dust size modes. At heights close to $6.3 \mathrm{~km}$, the BAE profile returns to levels of 0.8 to 0.95 , thereafter decreasing down to 0.4 to 0.5 around $7 \mathrm{~km}$.

Regarding the entire altitude range ( 2 to $7.5 \mathrm{~km}$ ) of dust loading above the ABL, the shape of the size fraction distribution in the observed three distinct dust layers appears to be inverted as compared with the typical one because the coarser dust size-modes (in the upper two layers) are located above the finer ones (in the lower "twin-peak" layer). This particle size-mode distribution can qualitatively be explained referring to the lower part of the HYSPLIT diagram shown in Fig. 6(b). As can be seen there, the height-related order of the three backward trajectories ending above Sofia within the time interval of lidar measurements has been inverted during the transport. The trajectory (colored in green) that appears above the lidar site at an altitude of $7 \mathrm{~km}$ passes at significantly lower heights (1 to $2.5 \mathrm{~km}$ ) over the Sahara; i.e., not very far from the desert surface, thus making it possible to capture large dust particles. At the same time, 
the (red colored) trajectory appearing as the lowest one over the lidar site (at $2.5 \mathrm{~km}$ ) crosses the desert atmosphere at altitudes of 4 to $5 \mathrm{~km}$, thus likely capturing finer dust particle modes. The intermediate (blue) trajectory ends above Sofia at approximately the same height (4 km) as over the Sahara Desert crossing the ABL of the latter, indicating transport of dust fractions of moderate size. The anomalous distribution of dust particle size fractions observed becomes reasonable taking into account the discussed above height-related reordering of the corresponding backward trajectories.

Figure 10(c) shows vertical profiles of $T$, DP, and RH of the atmospheric air over Sofia at 12:00 UTC on February 1, 2018. The meteorological conditions are nearly like the ones observed on February 24, 2017, [as can be seen in Fig. 9(c)] but exhibiting some specifics. Similarly, a temperature inversion is present at a height of about $2 \mathrm{~km}$, accompanied by a relatively dry zone above it extending up to $4 \mathrm{~km}$ (RH near 20\%), which very likely can be ascribed to the presence of dry and warm Saharan air masses. Accordingly, this results in a well-expressed separation of the $T$ and DP profiles above the inversion, defining conditions not favorable for ice nucleation, which explains the observed absence of cirrus clouds. As a feature to be noted, the air temperature near the surface (about $8^{\circ} \mathrm{C}$ ) is lower compared with the ones in the previously considered two cases. This fact can be explained by the lack of significant penetration of Saharan air masses down to the surface, likely due to the presence of temperature inversion near the top of the local ABL.

\subsubsection{Lidar observations conducted on February 18, 2019}

Figure 11 presents vertical profiles, up to a height of $9 \mathrm{~km}$, of the optical and microphysical parameters of atmospheric aerosols/dust derived from lidar measurements carried out in the time interval 16:20 to 18:30 UTC on February 18, 2019, as well as the meteorological profiles for that day.

Vertical profiles of the aerosol BSC for the two lidar wavelengths averaged over the entire measurement period are shown in Fig. 11(a). As can be seen, during the lidar measurements on this day, a distinct confinement of the atmospheric aerosols was observed in the bottom height range of up to about $3 \mathrm{~km}$. Above that height, the free of aerosols troposphere is extended, in particular without water or cirrus clouds. Another distinguishing feature of the aerosol distribution in this case is its well-expressed vertical stratification in three distinctly outlined, approximately smooth, layers with peaks centered at altitudes of $0.35,1.2$, and $2.18 \mathrm{~km}$. Referring to Fig. 7(a), it can be seen that this distinct aerosol field stratification has remained constant

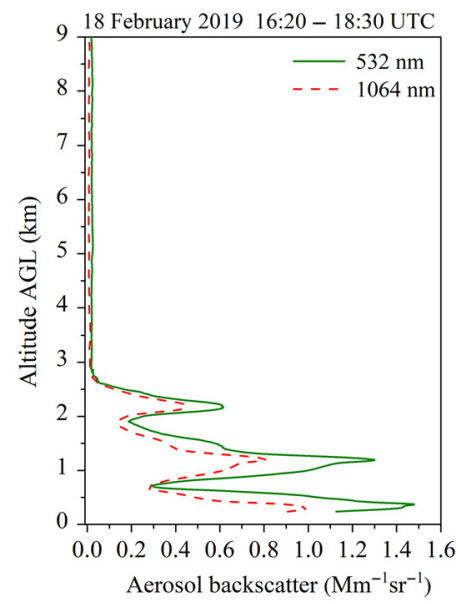

(a)

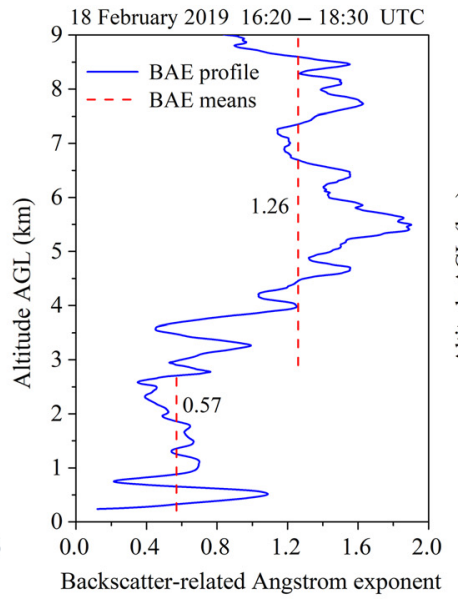

(b)

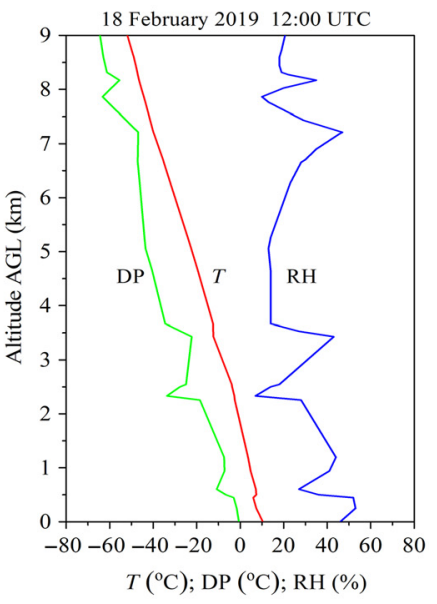

(c)

Fig. 11 Lidar measurements carried out on February 18, 2019: (a) vertical profiles of the aerosol BSC at the two laser wavelengths 532 and $1064 \mathrm{~nm}$. (b) The corresponding aerosol BAE derived from the lidar measurements. Mean BAE values of characteristic profile parts are labeled and shown by dashed lines. (c) Meteorological radiosonde data (temperature, $T$; dew point, DP; and relative humidity, $\mathrm{RH})$. 
Deleva et al.: Lidar study of unusual winter Saharan dust loads above Sofia, Bulgaria: impacts...

throughout the lidar measurements. It is worth noting that the lowermost layer nearly coincides with the seasonal ABL for the Sofia area.

The maximum BSC values for the three registered layers (in bottom up sequence) are 1.47/ $1.0,1.3 / 0.8$, and $0.62 / 0.5 \mathrm{Mm}^{-1} \mathrm{sr}^{-1}$ at $532 / 1064 \mathrm{~nm}$, respectively. The BSC values for the lowest layer are not very different from those traditionally measured for the local ABL. The ones corresponding to the two upper layers are also not very high, exceeding slightly the ones measured on February 1, 2018, but being significantly lower than those observed on February 17, 2014, and February 24, 2017. This indicates an event of low-to-moderate intensity of Saharan dust transport to the region of measurement. Such a conclusion is supported by the corresponding backward trajectories shown in Fig. 7(b) for the heights of the upper two registered layers that pass only partly over the western coastal Sahara region. The complete absence of cirrus clouds during the measurement is an indirect indication for the absence of a frontal system entering the atmosphere above the Sofia region. Therefore, the observed layers of moderatedensity desert aerosols are more likely residual from preceding dust intrusions, with possible contribution of a low-intensity dust load on the day of measurement. Such an inference is supported by the analysis of previous BSC-DM data showing that the Saharan dust layers recorded on that day are part of a significant, long-lasting episode of east-northeastward transport of warm air masses from North Africa covering significant parts of Europe, including Bulgaria. Furthermore, both the duration and intensity of this transfer, which began around 3 February and ended around 21 February, are remarkably high and atypical for the winter period in Bulgaria, exceeding standards even for the usual intense spring-summer dust-transport events. Such duration and intensity can be considered potential indications of possible deviations in the winter cycle of air circulations in North Africa and the Mediterranean basin.

Observations of intense Saharan dust transport over Sofia were also implemented with our lidar system on several other dates within the above-mentioned period, when weather conditions allowed (this remains beyond the scope of the present work).

Figure 11(b) shows the BAE vertical profile obtained on the basis of the BSC profiles of Fig. 11(a). As previously, vertical dashed lines denote the average BAE values obtained for the described above two characteristic altitude ranges of the profiles: 0.57 for dust-containing aerosol layers in the range 0.24 to $2.8 \mathrm{~km}$ and 1.26 for the free troposphere section 3 to $9 \mathrm{~km}$. The latter BAE value practically coincides with the typical average BAE value for background aerosols ${ }^{8}$ in the case of SA. ${ }^{49}$ Because the three aerosol layers are well separated from each other, which may suggest a different origin and/or aerosol composition, the BAE was also determined for each of them individually. The BAE partial values thus obtained are as follows: 0.79 for the lowest, 0.63 for the middle, and 0.45 for the top layers. The BAE value for the top layer clearly indicates the dominance of coarse aerosol modes in the over-micron size range, which is characteristic of the Saharan dust registered above Sofia. ${ }^{8}$ This is why we assume that this layer is composed predominantly of desert aerosols. The bottom layer BAE value is slightly lower than traditionally measured ones $(\sim 1)$ for the local ABL, within which it falls, and is significantly higher than that of the top layer. On the other hand, the intermediate BAE value of the middle layer located at and just above the ABL top is much closer to that of the upper dust layer and significantly lower than that typical of the ABL. This gives us reason to consider the two lower aerosol layers a mixture of desert and local aerosols, with the lowest layer being dominated by local aerosols and the middle one dominated by Saharan aerosols.

The above conclusions are consistent with the meteorological profiles for the date in question, presented in Fig. 11(c). As can be seen, the temperature measured at the surface $\left(\sim 10^{\circ} \mathrm{C}\right)$ is moderately higher than the climate normal average monthly temperature for Sofia in February. This also agrees well with the values of the composite temperature anomaly that can be seen in Fig. 3(d). The RH varies with low values, mainly from $20 \%$ to $50 \%$, over the whole height range shown, with a pronounced minimum of $8 \%$ at a height of $2.3 \mathrm{~km}$, coinciding well with the center of the top Saharan dust layer. We associate these low-humidity values, extending up to significant heights, with the influence of considerable amounts of Saharan dust over Sofia in the above-mentioned previous time period of unusual for the season active transfer of warm and dry air masses from North Africa. Expectedly, the DP profile remains far from the $T$ one. 


\section{Discussion and Summary}

Based on the analysis of the lidar observations of atypical winter intrusions of warm air masses from North Africa carrying desert dust over the region of Sofia, Bulgaria, a summarizing discussion of the results obtained is presented below.

The episodes considered of long-range transport of Saharan dust over the city of Sofia during the months of February in four years of the last decade can be considered representative with respect to the objectives of this study because they present dust load events with various durations, intensity, and vertical stratification of the invading aerosol fields. In addition, the cases presented include lidar measurements conducted in the beginning, near the height, and in the end of the events under consideration. The significant frequency and duration of these atypical events for the winter season indicate that they become more common and repetitive, very likely due to synoptic-scale changes in the seasonal cycle of the North African and Mediterranean air circulations. A convincing support to such a deduction is provided in particular in one of the dust load events considered here (episode 4) that lasted continuously for about 20 days (February 3 to 21, 2019).

The vertical two-wavelength profiling of the aerosol optical parameters shows variations in the maximum BSC values for the dust-containing aerosol layers within quite a wide range ( 0.9 to $8.1 \mathrm{Mm}^{-1} \mathrm{sr}^{-1}$ at $532 \mathrm{~nm}$ and 0.6 to $5.1 \mathrm{Mm}^{-1} \mathrm{sr}^{-1}$ at $1064 \mathrm{~nm}$ ), in good agreement with the available forecast data of the BSC-DM model for the dust load intensity and dust concentration.

When the intrusions of desert aerosols spread over wide altitudinal ranges of several kilometers (episodes 1 to 3), a variety of aerosol density stratification configurations is observed. It involves the formation of broad, nearly smooth profile shapes (case 1), as well as more complex structures comprising sublayers (cases 2 and 3), centered at and around the upper boundary of the ABL (case 2) or high above it (case 3). These peculiarities are mainly attributed to the lidar measurements being conducted in the initial or middle phase of the dust load event. Thus they are accompanied by stronger temporal dynamics of the aerosol density distribution, in accordance with the higher intensity and dynamics of the intrusion events themselves. By contrast, when the lidar observations are carried out during the final, damping period of the event (case 4), the dustcontaining aerosol layers are well separated and outlined and characterized by a very low dynamics of aerosol density variations.

The average BAE values obtained for the dust-containing aerosol layers are in the range 0.4 to 0.9 , indicating domination of aerosol fractions in the near over-micron size range. These BAE values are close to the ones typically measured over Sofia in other seasons, accounting for the naturally coarse particles of the Saharan dust, but which have undergone processes of partial depletion of the largest fractions during the long-range transport (about $2000 \mathrm{~km}$ ) to the measurement site. The analysis of the BAE vertical distributions, indicative of the height distribution of the aerosol size fractions, shows observations of a normal distribution, whereby the aerosol particle size decreases upward (case 2), reflecting the natural stratification due to sedimentation processes during transport. The deviations from this natural distribution of aerosol size modes observed at low altitudes, mainly in and slightly above ABL (1 to $1.5 \mathrm{~km}$ ), result from a blurring of the ABL boundary and the corresponding interpenetration and mixing of local and desert aerosols, with the dominance of the fine fractions (case 1) or large ones (case 3). In the latter case, anomalous appearance of dense layers of coarse Saharan dust fractions was observed at significant altitudes ( 5 to $6 \mathrm{~km}$ ), located above much smaller aerosol size modes. This atypical vertical distribution is explained by the HYSPLIT model transport history of the layers, revealing significant convective uplift of the coarse desert aerosols during the transport, which end at the observed height above Sofia in the time period of lidar measurement.

The comparative analysis of the data and the results from the lidar studies presented with the corresponding meteorological data shows a good agreement between them. This confirms unequivocally the serious perturbing effect of the invading warm air masses on the local weather in the coldest winter months in question. In particular, the air temperature in a close vicinity to the surface shows values significantly higher (by $5^{\circ} \mathrm{C}$ to $15^{\circ} \mathrm{C}$ ) than those normally measured in Sofia in the considered period of the year. This trend is more pronounced in the first days of the dust-load events (cases 1 and 2), while it is less apparent in the later stages following the initial intrusion (cases 3 and 4). The water content of the atmospheric air and the water condensation processes are also highly affected. These find expression in a significant decrease of the RH 
within the altitudinal intervals dominated by desert aerosols, as well as in a departure from favorable dew conditions. Thus the cloud-formation and precipitation regimes are influenced. The significance of this influence is particularly high in the case of durable events of Saharan dust transport, such as the one in the period February 03 to 21, 2019 (case 4). Another important aspect of the impact of Sahara air masses on the local weather conditions is related to temperature inversions. On the one hand, warm air masses, when invading altitudes close to but above the ABL top, create favorable conditions for the formation of $T$-inversions, which act as a natural barrier preventing aerosol convection. On the other hand, desert air masses, being frequently present both below and above the inversions, reduce their barrier effect. This favors the processes of mixing and interaction of Saharan aerosols with the local ones, forming specific aerosol layering, composition, and particle size distributions. The mutual penetration and mixing is stronger in the events of the desert aerosols advection at altitudes around the ABL (case 3) and less pronounced at higher altitudes of loading (case 4).

\section{Acknowledgments}

This research was supported by the Bulgarian National Science Fund (Grant No. KP-06-N28/10/ 2018) and the Bulgarian Ministry of Education and Science (support for ACTRIS BG, part of the Bulgarian National Roadmap for Research Infrastructure). The financial support was also acknowledged for EARLINET in the ACTRIS Research Infrastructure by the European Union's Horizon 2020 Research and Innovation Program under Grant Agreements No. 654109 (ACTRIS-2) and No. 871115 (ACTRIS IMP). The authors would like to acknowledge data and images from the NMMB/BSC-Dust and BSC-DREAM8b models operated by the Barcelona Supercomputing Center, the NCEP Reanalysis data provided by the NOAA/OAR/ESRL PSL, Boulder, Colorado, USA, from their website, and the NOAA Air Resources Laboratory for the provision of the HYSPLIT transport and dispersion model and READY website used in this publication.

\section{References}

1. D. L. Hartmann, Global Physical Climatology, 2nd ed., Elsevier Science, Amsterdam (2015).

2. B. A. Maher et al., "Global connections between Aeolian dust, climate and ocean biogeochemistry at the present day and at the last glacial maximum," Earth Sci. Rev. 99, 61-97 (2010).

3. J. Prospero et al., "Environmental characterization of global sources of atmospheric soil dust identified with the Nimbus 7 Total Ozone Mapping Spectrometer (TOMS) absorbing aerosol product," Rev. Geophys. 40 (1), 1002 (2002).

4. N. Kubilay et al., "An illustration of the transport and deposition of mineral dust onto the eastern Mediterranean," Atmos. Environ. 34, 1293-1303 (2000).

5. D. Meloni et al., "Seasonal behavior of Saharan dust events at the Mediterranean island of Lampedusa in the period 1999-2005," Atmos. Environ. 41(14), 3041-3056 (2007).

6. A. Papayannis et al., "Systematic lidar observations of Saharan dust over Europe in the frame of EARLINET (2000-2002)," J. Geophys. Res. 113, D10204 (2008).

7. O. Soupiona et al., "Long-term systematic profiling of dust aerosol optical properties using the EOLE NTUA lidar system over Athens, Greece (2000-2016)," Atmos. Environ. 183, 165-174 (2018).

8. Z. Y. Peshev et al., "Lidar observations of long-range transported Saharan dust over Sofia, Bulgaria: a case study of dust mixed with local aerosols," J. Appl. Remote Sens. 10(3), 036009 (2016).

9. E. Marinou et al., "Three-dimensional evolution of Saharan dust transport towards Europe based on a 9-year EARLINET-optimized CALIPSO dataset," Atmos. Chem. Phys. 17, 5893-5919 (2017).

10. A. Russo et al., "Saharan dust intrusions in the Iberian Peninsula: predominant synoptic conditions," Sci. Total Environ. 717, 137041 (2020). 
Deleva et al.: Lidar study of unusual winter Saharan dust loads above Sofia, Bulgaria: impacts...

11. G. Varga, "Changing nature of Saharan dust deposition in the Carpathian Basin (Central Europe): 40 years of identified North African dust events (1979-2018)," Environ. Intern. 139, 105712 (2020).

12. A. Deleva et al., "Lidar observations of Saharan dust loads above Sofia, Bulgaria: dust layers extending throughout the troposphere (a case study)," J. Appl. Remote Sens. 14, 014504 (2020).

13. G. Gobbi et al., "An inclusive view of Saharan dust advections to Italy and the Central Mediterranean," Atmos. Environ. 201, 242-256 (2019).

14. P. T. Nastos, "Meteorological patterns associated with intense Saharan dust outbreaks over Greece in winter," Advances in Meteorol. 2012, 1-17 (2012).

15. G. Varga et al., "Unusual Saharan dust events in the Carpathian Basin (Central Europe) in 2013 and early 2014," Weather 69(11), 309-313 (2014).

16. G. Titos et al., "Spatiotemporal evolution of a severe winter dust event in the western Mediterranean: aerosol optical and physical properties," J. Geophys. Res. Atmos. 122, 4052-4069 (2017).

17. A. Deleva et al., "Unusual wintertime transport of Saharan dust to Sofia, Bulgaria, detected by lidar," Proc. SPIE 11047, 1104711 (2019).

18. A. J. Fernández et al., "Extreme, wintertime Saharan dust intrusion in the Iberian Peninsula: lidar monitoring and evaluation of dust forecast models during the February 2017 event," Atmos. Res. 228, 223-241 (2019).

19. C. Rodriguez-Navarro et al., "Mineralogy and physicochemical features of Saharan dust wet deposited in the Iberian Peninsula during an extreme red rain event," Atmos. Chem. Phys. 18, 10089-10122 (2018).

20. C. Córdoba-Jabonero et al., "Performance of a dust model to predict the vertical mass concentration of an extreme Saharan dust event in the Iberian Peninsula: comparison with continuous, elastic, polarization-sensitive lidars," Atmos. Environ. 214, 116828 (2019).

21. F. Oduber et al., "Unusual winter Saharan dust intrusions at Northwest Spain: air quality, radiative and health impacts," Sci. Total Environ. 669, 213-228 (2019).

22. L. Mărmureanu et al., "Orange snow-a Saharan dust intrusion over Romania during winter conditions," Remote Sens. 11, 2466 (2019).

23. F. De Longueville et al., "Saharan dust impacts on air quality: what are the potential health risks in West Africa?" Hum. Ecol. Risk Assess. 19(6), 1595-1617 (2013).

24. P. Knippertz and J.-B. W. Stuut, Mineral Dust: A Key Player in the Earth System, Springer, Cham (2014).

25. C. Tomasi, S. Fuzzi, and A. Kokhanovski, Atmospheric Aerosols: Life Cycles and Effects on Air Quality and Climate, Wiley-VCH, Weinheim (2017).

26. O. A. Choobari, P. Zawar-Reza, and A. Sturman, "The global distribution of mineral dust and its impacts on the climate system: a review," Atmos. Res. 138, 152-165 (2014).

27. Q. Wang, J. Gu, and X. Wang, "The impact of Sahara dust on air quality and public health in European countries," Atmos. Environ. 241, 117771 (2020).

28. J. Helmert et al., "On the direct and semidirect effects of Saharan dust over Europe: a modeling study," J. Geophys. Res. 112, D13208 (2007).

29. L. Mona et al., "Lidar measurements for desert dust characterization: an overview," Adv. Meteorol. 2012, 356265 (2012).

30. "The EARLINET publishing group 2000-2015, EARLINET Saharan Dust 2000-2015," World Data Center for Climate (WDCC) at DKRZ (2018).

31. A. Ångström, "On the atmospheric transmission of Sun radiation and on dust in the air," Geogr. Ann. 11, 156-166 (1929).

32. A. Ångström, "The parameters of atmospheric turbidity," Tellus 16, 64-75 (1964).

33. G. L. Schuster et al, "Ångström exponent and bimodal aerosol size distributions," J. Geophys. Res. 111, D07207 (2006).

34. M. Del Guasta, "Daily cycles in urban aerosols observed in Florence (Italy) by means of an automatic 532-1064 nm LIDAR," Atmos. Environ. 36(17), 2853-2865 (2002).

35. I. Veselovskii et al., "Retrieval of optical and physical properties of African dust from multiwavelength Raman lidar measurements during the SHADOW campaign in Senegal," Atmos. Chem. Phys. 16, 7013-7028 (2016). 
Deleva et al.: Lidar study of unusual winter Saharan dust loads above Sofia, Bulgaria: impacts...

36. G. Pérez et al., "A long Saharan dust event over the western Mediterranean: lidar, Sun photometer observations, and regional dust modelling," J. Geophys. Res. 111, D15214 (2006).

37. A. Chaikovsky et al., "Methodology to retrieve atmospheric aerosol parameters by combining ground-based measurements of multi-wavelength lidar and Sun sky-scanning radiometer," Proc. SPIE 4678, 257-268 (2002).

38. A. Chaikovsky et al., "Lidar-radiometer inversion code (LIRIC) for the retrieval of vertical aerosol properties from combined lidar/radiometer data: development and distribution in EARLINET," Atmos. Meas. Tech. 9, 1181-1205 (2016).

39. A. Tsekeri et al., "GARRLiC and LIRIC: strengths and limitations for the characterization of dust and marine particles along with their mixtures," Atmos. Meas. Tech. 10, 4995-5016 (2017).

40. G. Pappalardo et al., "EARLINET: towards an advanced sustainable European aerosol lidar network," Atmos. Meas. Tech. 7, 2389-2409 (2014).

41. Aerosol, "Clouds and trace gases (ACTRIS) research infrastructure," https://www.actris.eu (accessed 15 July 2020).

42. Sofia, "Bulgaria weather history," https://www.wunderground.com/history/daily/bg/sofia/ LBSF (accessed on 15 July 2020).

43. A. Deleva et al., "Raman-elastic-backscatter lidar for observations of tropospheric aerosol," Proc. SPIE 7027, 70270Y (2008).

44. D. Klett, "Stable analytical inversion solution for processing lidar returns," Appl. Opt. 20, 211-220 (1981).

45. G. Fernald, "Analysis of atmospheric lidar observations: some comments," Appl. Opt. 23(5), 652-653 (1984).

46. C. Cattrall et al., "Variability of aerosol and spectral lidar and backscatter and extinction ratios of key aerosol types derived from selected Aerosol Robotic Network locations," J. Geophys. Res. 110, D10S11 (2005).

47. D. Müller et al., "Aerosol-type-dependent lidar ratios observed with Raman lidar," J. Geophys. Res. 112, D16202 (2007).

48. M.-H. Kim, S.-W. Kim, and A. H. Omar, "Dust lidar ratios retrieved from the CALIOP measurements using the MODIS AOD as a constraint," Remote Sens. 12, 251 (2020).

49. United States Committee on Extension to the Standard Atmosphere (COESA), "U.S. Standard Atmosphere, 1976," U.S. Government Printing Office, Washington, D.C. (1976).

50. V. A. Kovalev and W. E. Eichinger, Elastic Lidar: Theory, Practice, and Analysis Methods, John Wiley \& Sons, Inc., Hoboken, New Jersey (2004).

51. A. Berjón et al., "A 10-year characterization of the Saharan Air Layer lidar ratio in the subtropical North Atlantic," Atmos. Chem. Phys. 19, 6331-6349 (2019).

52. S. Basart et al., "Development and evaluation of the BSC-DREAM8b dust regional model over Northern Africa, the Mediterranean and the Middle East," Tellus B 64, 18539 (2012).

53. C. Pérez et al., "An online mineral dust aerosol model for MESO to global scales: model description, annual simulations and evaluation," Atmos. Chem. Phys. 11, 13001-13027 (2011).

54. K. Haustein et al, "Atmospheric dust modeling from MESO to global scales with the online NMMB/BSC-dust model-Part 2: experimental campaigns in Northern Africa," Atmos. Chem. Phys. 12, 2933-2958 (2012).

55. A. F. Stein et al., "NOAA's HYSPLIT atmospheric transport and dispersion modeling system," Bull. Am. Meteorol. Soc. 96, 2059-2077 (2015).

56. G. Rolph, A. Stein, and B. Stunder, "Real-time environmental applications and display system: READY," Environ. Modell. Softwares 95, 210-228 (2017).

57. Executive Environment Agency (ExEA), "Ministry of environment and water-Bulgaria," National System for Environmental Monitoring, http://www.eea.government.bg/kav/ (accessed 15 July 2020).

58. European Environment Agency (EEA), "Download of air quality data," https://discomap .eea.europa.eu/map/fme/AirQualityExport.htm (accessed 15 July 2020).

59. E. Kalnay et al., "The NCEP/NCAR Reanalysis 40-year Project," Bull. Amer. Meteor. Soc. 77, 437-471 (1996). 
Deleva et al.: Lidar study of unusual winter Saharan dust loads above Sofia, Bulgaria: impacts...

60. L. Garcia-Carreras et al., "The turbulance structure and diurnal growth of the Saharan atmospheric boundary layer," J. Atmos. Sci. 72, 693-713 (2015).

61. J. Cuesta et al., "Dynamical mechanisms controlling the vertical redistribution of dust and the thermodynamic structure of the West Saharan atmospheric boundary layer during summer," Atmos. Sci. Lett. 10, 34-42 (2009).

62. M. Gammo, "Thickness of the dry convection and large-scale subsidence above deserts," Bound.-Layer Meteorol. 79, 265-278 (1996).

63. N. Ajtai et al., "Multi-sensor observation of a Saharan dust outbreak over Transylvania, Romania in April 2019," Atmosphere 11, 364 (2020).

64. A. Kamei et al., "Volcanic aerosol layer observed by shipboard lidar over the tropical western Pacific," Sci. Online Lett. Atmos. 2, 1-4 (2006).

65. J. Gasteiger et al., "Particle settling and vertical mixing in the Saharan Air Layer as seen from an integrated model, lidar, and in situ perspective," Atmos. Chem. Phys. 17, 297-311 (2017).

66. Z. Peshev et al., "Two-wavelength lidar characterization of optical, dynamical, and microphysical properties of Saharan dust layers over Sofia, Bulgaria," Proc. SPIE 9447, 94470R (2015).

Biographies of the authors are not available. 